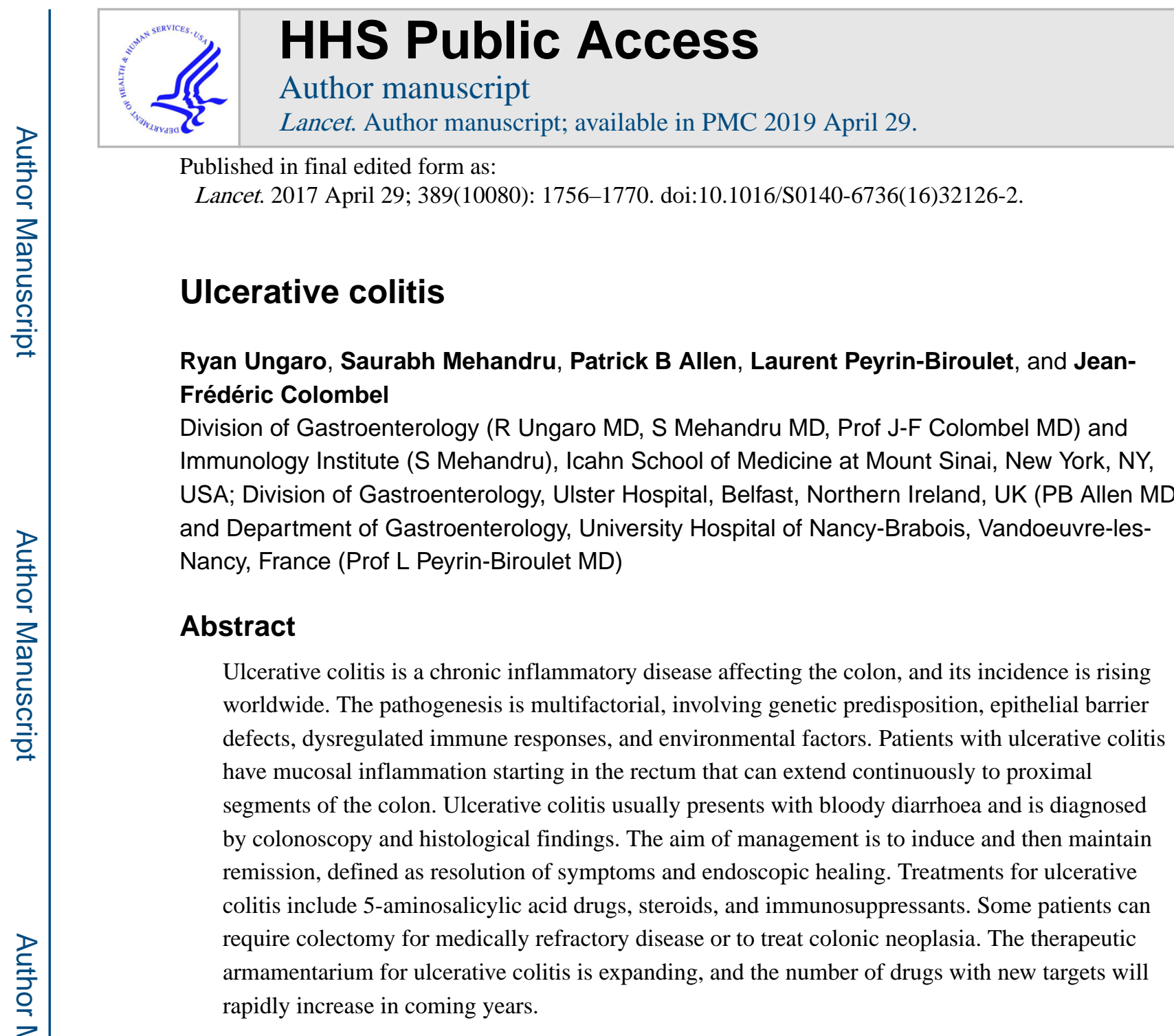

Published in final edited form as:

Lancet. 2017 April 29; 389(10080): 1756-1770. doi:10.1016/S0140-6736(16)32126-2.

\title{
Ulcerative colitis
}

Ryan Ungaro, Saurabh Mehandru, Patrick B Allen, Laurent Peyrin-Biroulet, and JeanFrédéric Colombel

Division of Gastroenterology (R Ungaro MD, S Mehandru MD, Prof J-F Colombel MD) and Immunology Institute (S Mehandru), Icahn School of Medicine at Mount Sinai, New York, NY, USA; Division of Gastroenterology, Ulster Hospital, Belfast, Northern Ireland, UK (PB Allen MD); and Department of Gastroenterology, University Hospital of Nancy-Brabois, Vandoeuvre-lesAbstract

Ulcerative colitis is a chronic inflammatory disease affecting the colon, and its incidence is rising worldwide. The pathogenesis is multifactorial, involving genetic predisposition, epithelial barrier defects, dysregulated immune responses, and environmental factors. Patients with ulcerative colitis have mucosal inflammation starting in the rectum that can extend continuously to proximal segments of the colon. Ulcerative colitis usually presents with bloody diarrhoea and is diagnosed by colonoscopy and histological findings. The aim of management is to induce and then maintain emission, defined as resolution of symptoms and endoscopic healing. Treatments for ulcerative colitis include 5-aminosalicylic acid drugs, steroids, and immunosuppressants. Some patients can require colectomy for medically refractory disease or to treat colonic neoplasia. The therapeutic rapidly increase in coming years.

Correspondence to: Professor Jean-Frédéric, Colombel, Division of Gastroenterology, Icahn School of Medicine at Mount Sinai, New York, NY 10029, USA, jean-frederic.colombel@mssm.edu.

See Online for appendix

\section{Contributors}

RCU, SM, and PBA did the literature search, wrote the manuscript and drafted the figures. LP-B and J-FC wrote and revised manuscript. All authors critically revised the manuscript and approved the final version of the manuscript.

Declaration of interests

RCU has no conflicts of interest. SM has served as a consultant for Pfizer Inc and receives research funding support from Takeda Pharmaceuticals. PBA has received Speaker fees for MSD, AbbVie, Allergen, Ferring, Warner Chilcott, and Napp. LP-B has received consulting fees from Merck, AbbVie, Janssen, Genentech, Mitsubishi, Ferring, Norgine, Tillots, Vifor, Therakos, Pharmacosmos, Pilège, Bristol-Myers Squibb, Union Chimique Belge (UCB) Pharmaceuticals, Hospira, Celltrion, Takeda, Biogaran, BoerhingerIngelheim, Lilly, Pfizer, HAC Pharma, Index Pharmaceuticals, Amgen, Sandoz, Forward Pharma GmbH, Celgene, Biogen, Lycera, and Samsung Bioepis, and lecture fees from Merck, AbbVie, Takeda, Janssen, Takeda, Ferring, Norgine, Tillots, Vifor, Therakos, Mitsubishi, and HAC Pharma. J-FC has served as consultant or advisory board member for AbbVie, Amgen, AstraZeneca, ABScience, Boehringer, Bristol-Meyers Squibb, Celgene, Celltrion, Danone, Enterome, Evidera, Ferring, Genentech, Giuliani SPA, Given Imaging, Janssen \& Janssen, Immune Pharmaceuticals, Intestinal Biotech Development, Kyowa Kirin Pharma, Lilly, Medimmune, Merck Sharp Dohme, Merck \& Co, Millennium Pharmaceuticals Inc, Navigant Consulting, Neovacs, Nestle Nutrition Sciences Partner, Nutrition Science Partners Ltd, Pfizer, Prometheus Laboratories, Protagonist Therapies, Receptos, Sanofi, Schering Plough Corporation, Second Genome, Shire, Takeda, Teva Pharmaceuticals, Tigenix, UCB, UEGW AbbVie Advisory Board, UEGW AbbVie Symposium, Vertex, and Dr August Wolff GmbH Co. 


\section{Introduction}

Ulcerative colitis is a chronic, idiopathic inflammatory disease that affects the colon, most commonly affiicting adults aged $30-40$ years and resulting in disability. ${ }^{1,2}$ It is characterised by relapsing and remitting mucosal inflammation, starting in the rectum and extending to proximal segments of the colon. The aim of therapy is to induce and maintain clinical and endoscopic remission. ${ }^{3}$ Aminosalicylates are the main choice of treatment for mild to moderate ulcerative colitis, topical and systemic steroids can be used to treat ulcerative colitis flares, while immunosuppressants and biological drugs are used in moderate to severe disease. Colectomy is needed in up to $15 \%$ of patients with ulcerative colitis. ${ }^{4}$ The annual direct and indirect costs related to ulcerative colitis are estimated to be as high as $€ 12.5-29.1$ billion in Europe and US\$8.1-14.9 billion in the USA. ${ }^{5}$

\section{Epidemiology}

No sex predominance exists in ulcerative colitis. ${ }^{6-8}$ The peak age of disease onset is between ages 30 years and 40 years. ${ }^{7,9}$ The incidence and prevalence of ulcerative colitis have been increasing over time worldwide (figure 1). ${ }^{10}$ The highest incidences of ulcerative colitis have been reported in northern Europe ( 24.3 per 100 000), Canada (19.2 per 100 000), and Australia (17.4 per 100 000). ${ }^{6,10,11}$ Prevalence rates are highest in Europe (505 per 100 000), Canada (248 per 100 000), and the USA (214 per 100 000). 7,10,12,13 Within Europe, there appears to be differences in ulcerative colitis incidence, with countries located in the western and northern regions having higher incidences than eastern countries. ${ }^{14}$ The risk of developing ulcerative colitis in children of migrants from low-incidence to highincidence countries is similar to non-immigrants. ${ }^{15-17}$ Less data is available from developing countries; however, recognition of ulcerative colitis is increasing in Asia, the Middle East, and South America. ${ }^{18-21}$

\section{Risk factors}

$8-14 \%$ of patients with ulcerative colitis have a family history of inflammatory bowel disease and first-degree relatives have four times the risk of developing the disease. ${ }^{22,23}$ Jewish populations have higher rates of ulcerative colitis than other ethnicities. ${ }^{24,25}$ Genome-wide association studies have identified 200 risk loci for inflammatory bowel disease to date, with most genes contributing to both ulcerative colitis and Crohn's disease phenotypes. ${ }^{26,27}$ Examples of loci associated with increased ulcerative colitis susceptibility include human leukocyte antigen and genes associated with barrier function, such as $H N F 4 A$ and $C D H 1 .^{27,28}$ However, genetics only explain $7.5 \%$ of disease variance, have little predictive capacity for phenotype, and currently are of limited clinical use. ${ }^{27,28}$

The rising incidence of ulcerative colitis worldwide suggests the importance of environmental factors in its development. Former cigarette smoking is one of the strongest risk factors associated with ulcerative colitis (odds ratio [OR] 1.79, 95\% CI 1.37-2.34), while active smokers are less likely to develop ulcerative colitis compared with former and non-smokers (OR $0.58,95 \%$ CI $0.45-0.75$ ) and have a milder disease course. ${ }^{24,29-32}$ Appendectomy appears to confer a protective effect against developing ulcerative colitis, 
especially when done for acute appendicitis in young patients. ${ }^{33}$ Patients newly diagnosed with ulcerative colitis are more likely than matched controls to have a history of gastroenteritis. ${ }^{34,35}$ Drugs, such as oral contraceptives, hormone replacement therapy, and non-steroidal anti-inflammatory drugs, have all been associated with an increased risk of ulcerative colitis, while antibiotic exposure has not. ${ }^{36-42}$ Breastfeeding appears to decrease the risk of ulcerative colitis, while urban living can increase the risk. ${ }^{43,44}$ Certain ulcerative colitis risk factors that are significant in developed countries might not have the same effect in developing Asian or Middle Eastern populations. For example, smoking might not have as strong an effect, appendectomy does not appear to decrease risk, and antibiotics have been found to be protective when comparing developed countries with developing Asian or Middle Eastern countries. ${ }^{40,41}$ Pooled data from 11 European prospective studies did not find an association between stress and new onset ulcerative colitis. ${ }^{45}$

\section{Pathophysiology}

Although existing literature often describes the pathogenesis of ulcerative colitis alongside that of Crohn's disease, important differences exist. Overview of the intestinal immune system in the healthy state and during ulcerative colitis is shown in figure 2. Colonic epithelial cells (colonocytes), and mucous barrier and epithelial barrier defects are strongly implicated in the pathogenesis of ulcerative colitis. The expression of peroxisome proliferator-activated receptor gamma (PPAR- $\gamma$ ), a negative regulator of NF- $\mathrm{kB}$-dependent inflammation, is reduced in the colonocytes of patients with ulcerative colitis, suggesting a causal link. ${ }^{46,47}$ Existing PPAR- $\gamma$ agonists are restricted by cardiac and metabolic toxicity. However, novel 5-aminosalicylic acid (5-ASA) analogues with greater PPAR- $\gamma$ agonistic activity are being developed. ${ }^{48}$ Autoantibodies against colonocyte-associated tropomyosins have been described in ulcerative colitis, ${ }^{49}$ but conclusive evidence classifying ulcerative colitis as an autoantibody-mediated disease is scarce. Colonocyte-associated defects within $X B P 1$, a key component of the endoplasmic reticulum stress response pathway, have been reported in ulcerative colitis. ${ }^{50}$

Alterations in trefoil factors, a family of goblet cell-derived proteins that are produced in response to mucosal injury and contribute to the integrity of the mucosal barrier, have been described in patients with ulcerative colitis. ${ }^{51,52}$ The contention that barrier function defects are the primary drivers of disease is supported by the fact that patients with active ulcerative colitis have depleted colonic goblet cells and a permeable mucus barrier. ${ }^{53}$

Dysbiosis is seen in patients with ulcerative colitis, although to a lesser degree than in patients with Crohn's disease. ${ }^{54}$ Decreased biodiversity, with a lower proportion of Firmicutes and increased Gamma-proteobacteria and Enterobacteriaceae, has been reported in patients with ulterative colitis. ${ }^{55}$ Additionally, patients with the disease have increased sulphite-reducing Deltaproteobacteria in the colon. ${ }^{56}$ However, it is unclear if dysbiosis is the cause or effect of mucosal inflammation.

The expression levels of Toll-like receptors 2 (TLR2) and TLR 4 are increased in colonocytes and the lamina propria in active ulcerative colitis, although it is unclear if the increase in expression is a cause or consequence of mucosal inflammation. ${ }^{57}$ Similarly, TLR4 
polymorphisms have been reported in patients with ulcerative colitis and Crohn's disease but their implications for disease pathogenesis are unclear. ${ }^{58}$ Activated neutrophils accumulate in the blood and colonic tissue of patients with active ulcerative colitis compared with normal volunteers. ${ }^{59}$ Dendritic cells in patients with ulcerative colitis have enhanced expression of costimulatory molecules and are likely to be first responders in the setting of a breach in barrier integrity. ${ }^{60}$

Innate lymphoid cells (ILCs) might be central in the pathogenesis of inflammatory bowel disease. ILC3 are major mediators of chronic intestinal inflammation. ${ }^{61}$ Furthermore, ILCs isolated from patients with active ulcerative colitis show increased gene expression of key ILC3 cytokines (IL17A and IL22), transcription factors (RORC and AHR), and cytokine receptors (including $I L 23 R$ ) ${ }^{62}$ The possibility that ILCs might be drivers of disease pathogenesis has led to a number of potential novel therapeutic targets.

Although elevated $\operatorname{IgM}$, IgA, and $\operatorname{IgG}$ concentrations are reported in inflammatory bowel disease, there is a disproportionate increase in IgG1 antibodies in patients with ulcerative colitis. It is not known whether B cells are drivers of disease pathogenesis or merely responsive to barrier disruption.

Current evidence implicates both innate and adaptive cellular immunity as key to disease pathogenesis. Earlier evidence suggested that ulcerative colitis is a modified T-helper-2 (Th2) disease, while Crohn's disease is Th1 driven. In support, colonic lamina propria cells from patients with ulcerative colitis were found to contain Th2-polarised $\mathrm{T}$ cells that produce interleukin-5 (IL-5). ${ }^{63}$ Additionally, $I L-4$ and $I L-13$ mRNA levels were significantly increased in rectal biopsies from patients with ulcerative colitis compared with patients in the control group. ${ }^{64}$ Subsequent data have further implicated IL-13 in the pathogenesis of ulcerative colitis. IL-13, produced by non-classical natural killer T cells (perhaps a member of the ILC family), is a key mediator of epithelial cytotoxicity and barrier dysfunction in ulcerative colitis. ${ }^{65,66}$

Extending the T-helper Th1/Th2 paradigm for Crohn's disease versus ulcerative colitis, data from 2014 show that a novel population of CD4-positive Th cells, which produce IL-9, are identified by the transcription factor PU.1 and contribute to the development of ulcerative colitis. ${ }^{67} \mathrm{Th} 9$ cells develop after undifferentiated Th (Th0) cells encounter MHC class IIantigen complexes in the presence of the cytokines transforming growth factor- $\beta$ and IL-4. IL-9 produced by Th9 cells inhibits cellular proliferation and repair, and has a negative effect on intestinal barrier function. Additionally, IL-9 modestly but significantly increases tissue concentrations of tumour necrosis factor-a (TNF-a).

Naive lymphocytes are imprinted during activation with specific trafficking programmes. Dendritic cells play a central part in this process by integrating environmental cues and inducing expression of specific integrins and chemokine receptors. For example, dendritic cells residing in Peyer's patches or small bowel draining lymph nodes metabolise vitamin A to produce retinoic acid and induce the expression of integrin $\alpha 4 \beta 7$ and CCR9 on T and B lymphocytes. Therefore, imprinted cells enter into circulation, and upon re-entering the gut vasculature they engage their respective ligands-MAdCAM-1 (for a 4 $\beta 7$ ) and CCL25 (for 
CCR9). While defects in mucosal homing have not yet been shown in patients with ulcerative colitis, therapeutic strategies targeting a $4 \beta 7$ interaction with MAdCAM have become major tools in the management of ulcerative colitis. ${ }^{68}$

\section{Clinical presentation and differential diagnosis}

Ulcerative colitis is a chronic disease affecting the colonic mucosa that most commonly presents with blood in the stool and diarrhoea. Up to $15 \%$ of patients can initially present with severe disease. ${ }^{69}$ Symptoms can include urgency, incontinence, fatigue, increased frequency of bowel movements, mucus discharge, nocturnal defecations, and abdominal discomfort (cramps), although abdominal pain tends to be less of a hallmark feature than in Crohn's disease. ${ }^{70}$ Fevers and weight loss can also be present in severe disease. Ulcerative colitis is classified by the extent of colonic involvement (figure 3). ${ }^{71}$ Clinical presentation might vary on the basis of disease extent. Patients with proctitis might predominantly have urgency and tenesmus (sensation of incomplete evacuation), while in pancolitis, bloody diarrhoea and abdominal pain might be more prominent. Up to $10 \%$ of patients with proctitis or left-sided colitis can suffer from paradoxical constipation. Physical examination might reveal signs of anaemia, abdominal tenderness, and blood on rectal exam. Abdominal distention and tympany on percussion might indicate colonic dilatation, requiring prompt radiological assessment. Patients with ulcerative colitis might have anal fissures or skin tags due to irritation from diarrhoea, but the presence of anal or perianal fistulas should raise suspicion for Crohn's disease. Clostridium diffi cile is an important precipitant of flares and is associated with an increased risk of surgery and mortality, and should be ruled out at diagnosis and flare-ups. ${ }^{72,73}$ The panel lists the differential diagnoses.

Extraintestinal manifestations can occur in about a third of patients with ulcerative colitis, and up to a quarter might have extraintestinal manifestations before inflammatory bowel disease diagnosis (appendix p 6). ${ }^{75,76}$ Peripheral arthritis appears to be the most common extraintestinal manifestation; primary sclerosing cholangitis and pyoderma gangrenosum are more common in ulcerative colitis than in Crohn's disease. ${ }^{75,76}$ The risk of venous thromboembolism in patients with inflammatory bowel disease is increased three to four times, and is greater when the patient is admitted with a flare or being treated with corticosteroids. ${ }^{77-80}$ Clinicians should have a high index of suspicion for venous thromboembolism, and hospitalised patients with ulcerative colitis should be prescribed venous thromboembolism prophylaxis. ${ }^{81}$

\section{Diagnostic investigations}

The diagnosis of ulcerative colitis is based on a combination of symptoms, endoscopic findings, histology, and the absence of alternative diagnoses. ${ }^{69,82}$ All patients with possible ulcerative colitis should have stool assessments (stool culture and Clostridium difficile assay) to rule out enteric superimposed infections. Patients might have anaemia, iron deficiency, leucocytosis, or thrombocytosis. Hypoalbuminaemia can be observed in severe disease, in which it is a predictor of colectomy and poor response to biological drugs. ${ }^{83,84}$ Markers of inflammation, such as ESR and C-reactive protein, can be elevated (severe ulcerative colitis) or normal (mild to moderate disease). Perinuclear antineutrophil 
cytoplasmic antibodies can be elevated in ulcerative colitis, but are non-specific and have low sensitivity $(0.55 \%, 95 \%$ CI $0.53-0.58)$ so are not recommended as a diagnostic test. 69,71,82,85 Non-invasive stool biomarkers are more specific for intestinal inflammation. ${ }^{86}$ Fecal calprotectin, a protein detectable in stool that correlates with increased neutrophils in the intestine, can be helpful in ruling out inflammatory bowel disease, since patients with low fecal calprotectin have a less than $1 \%$ chance of having inflammatory bowel disease. ${ }^{86-88}$ However, fecal calprotectin does not distinguish between various causes of intestinal inflammation so cannot be used as a definitive diagnostic tool in ulcerative colitis. ${ }^{69}$

Endoscopy with biopsies is the only way to establish the diagnosis of ulcerative colitis. Colonoscopy with intubation of the terminal ileum is recommended for patients with suspected inflammatory bowel disease. Classic endoscopic findings in ulcerative colitis include erythema, loss of normal vascular pattern, granularity, erosions, friability, bleeding, and ulcerations (appendix p 17). ${ }^{82,89}$ The disease generally begins in the rectum, extending proximally in a continuous, circumferential pattern. Rectal sparing or patchy disease can be the result of topical or systemic medications and should not necessarily be interpreted as evidence of Crohn's disease.${ }^{90}$ Mucosal inflammation often has a clear demarcation between inflamed and normal mucosa, although histological inflammation can be found in normal appearing mucosa. ${ }^{82,89}$ Ulcers in ulcerative colitis are always associated with mucosal inflammation in contrast with Crohn's disease, in which the surrounding mucosa can appear uninflamed. ${ }^{69}$ Up to $75 \%$ of patients with ulcerative colitis with distal disease also have an isolated area of inflammation around the appendiceal orifice, commonly known as a cecal patch. ${ }^{91,92}$ Up to $20 \%$ of patients with pancolitis can have mild inflammatory changes in the terminal ileum called backwash ileitis. ${ }^{89,93}$ Ileitis that is severe or seen in the absence of pancolitis should raise suspicion of Crohn's disease. An esophagogastroduodenoscopy should be performed in patients with symptoms of upper tract involvement to rule out Crohn's disease. ${ }^{93}$ At least two biopsies should be taken from six different areas (terminal ileum, ascending, transverse, descending, sigmoid colon, and rectum), including normal appearing areas, since inflammatory changes could become evident on microscopy. ${ }^{89}$ Suggestive histological findings include distortion of crypt architecture, crypt shortening, increased lymphocytes and plasma cells in the lamina propria (basal plasmacytosis), mucin depletion, and paneth cell metaplasia (appendix p 18). ${ }^{82,94}$ Generally, imaging studies are of limited use in establishing the diagnosis. In patients with acute severe ulcerative colitis, assessment for toxic megacolon (defined as mid-transverse colon dilation $>5.5 \mathrm{~cm}$ ) should be performed with a plain upright abdominal film. ${ }^{95} \mathrm{CT}$ and MRI might show a thickened, ahaustral colon, but are not sensitive or specific enough to be diagnostic tools. ${ }^{95}$

\section{Disease severity assessment}

Determining the severity and extent of ulcerative colitis is important for selecting the most appropriate treatment. Disease severity is typically classified as remission, mild, moderate, or severe. Numerous ulcerative colitis severity indices exist, but of the more commonly used are the Mayo score, Lichtiger score, and Simple Clinical Colitis Activity Index (appendix p 6). ${ }^{69,96-98}$ Endoscopy is essential in assessing disease severity since endoscopic healing is associated with improved remission rates and decreased risk of colectomy. ${ }^{99}$ Frequently used endoscopic ulcerative colitis scores include the endoscopy subscore of the Mayo score 
and the Ulcerative Colitis Endoscopic Index of severity (appendix p 9). ${ }^{96,100}$ Additionally, histological disease activity can be classified on the basis of histological scores such as the Robarts Histopathology index or Nancy index (appendix p 19). ${ }^{101,102}$ Ulcerative colitis severity scores account for disease activity at a single timepoint and do not take into account the entirety of the effect of ulcerative colitis. There is, therefore, a push to redefine disease severity using composite criteria that incorporate (1) disease effect on patient symptoms, quality of life, and disability; (2) measureable inflammatory burden using objective markers of disease activity and extent; and (3) disease course, including structural damage, number of flares, and extraintestinal manifestations. ${ }^{103}$

\section{Natural history}

At presentation, 30-60\% of patients with ulcerative colitis have proctitis, $16-45 \%$ have leftsided colitis, and $14-35 \%$ have extensive pancolitis in population-based studies (figure 3). ${ }^{4}$ Ulcerative colitis can progress proximally in $10-19 \%$ of patients after 5 years, and in up to $28 \%$ of patients at 10 years. ${ }^{4}$ Most patients with ulcerative colitis have a relapsing and remitting disease course with periodic flares. ${ }^{7}$ When ulcerative colitis flares are associated with proximal disease extension, patients are more likely to need immunosuppressants, biological drugs, or surgery. ${ }^{104,105}$ Age of onset appears to affect the disease course, since patients with disease onset after age 60 years tend to have milder disease compared with younger patients. ${ }^{106}$ Primary sclerosing cholangitis-associated ulcerative colitis could be a distinct phenotype, because it is more likely to be extensive, milder, and associated with rectal sparing and so-called backwash ileitis compared with patients with ulcerative colitis without primary sclerosing cholangitis. ${ }^{107}$ Risk factors for aggressive or complicated disease include a younger age at onset ( $<40$ years), pancolitis, lack of endoscopic healing while in clinical remission, deep ulcerations, and high concentrations of perinuclear antineutrophil cytoplasmic antibodies. ${ }^{104} \mathrm{~A}$ small number of patients (5-10\%) initially classified with ulcerative colitis might eventually have their diagnosis changed to Crohn's disease. ${ }^{7}$ Patients with ulcerative colitis can develop structural and functional damage to the colon, including benign strictures, colonic dysmotility, and anorectal dysfunction. ${ }^{2}$ Patients with the disease are at increased risk of colorectal cancer, but over time this risk has decreased and might be approaching the general population; however, the risk remains elevated in certain populations, such as those with long duration of disease, primary sclerosing cholangitis, and uncontrolled inflammation. ${ }^{108,109}$ The risk for surgery in ulcerative colitis has decreased over past decades, but is still substantial with the chance of needing surgery at 5 years being $11.6 \%$, and at 10 years being $15.6 \% .^{110}$ Risk factors for colectomy have been incorporated into a prediction model that includes age less than 40 years at diagnosis, extensive disease, need for systemic steroids, and elevated inflammatory markers. ${ }^{111}$ Patients with ulcerative colitis do not appear to have an overall increased mortality compared with the general population, but are more likely to have a disability preventing them from working. $1,112,113$

\section{Management}

The primary aim of medical management is to induce and maintain remission with the longterm goals of preventing disability, colectomy, and colorectal cancer. Targets for remission include resolution of clinical symptoms, defined as cessation of rectal bleeding and 
improvement in bowel habits, and endoscopic healing, which is frequently defined as an endoscopic Mayo score of zero or one. ${ }^{3,114}$ Patient symptoms and physician assessment can fail to correlate with the endoscopic activity of ulcerative colitis. ${ }^{15-117}$ It is important to directly assess mucosal and histological inflammation with colonoscopy, since endoscopic healing has been shown to greatly improve long-term clinical remission, decrease risk of colectomy, and limit corticosteroid use. ${ }^{99}$ The selection of medications is guided by disease severity and extent. A rapid step-up approach based on ulcerative colitis severity and treatment response while closely monitoring intestinal inflammation is recommended (figure 4, appendix). Early use of biological drugs should be considered in patients admitted to hospital with acute severe ulcerative colitis, as well as in steroid-refractory ulcerative colitis. Once remission is induced, medications can be continued or added to maintain remission. Disease extent can help inform therapeutic choices because patients with proctitis might only require topical therapy, such as suppositories, whereas patients with more extensive disease benefit from systemic therapy. Several guidelines are available to guide decision making. $82,114,118$

\section{Mild to moderate disease}

First-line therapy in mild to moderate disease is the 5-ASA drugs, which can be administered as suppositories, enemas, or oral formulations (figure 4). There does not appear to be any difference in efficacy or safety between different 5-ASA formulations. ${ }^{119}$

Sulfasalazine, which is metabolised to 5-ASA, appears to have similar efficacy to 5-ASA drugs, but tends to be less well tolerated. ${ }^{114}$ Patients with proctitis should be treated initially with 5-ASA suppositories since they directly target the site of inflammation and appear to be more effective than oral 5-ASA. ${ }^{114,118,120}$ In left-sided colitis, 5-ASA should be administered as an enema instead of a suppository in order to reach the splenic flexure. For patients with left-sided or extensive disease, it is recommended that oral 5-ASA be used in combination with topical 5-ASA to induce remission. ${ }^{114,118}$ Oral 5-ASA doses of $2 \mathrm{~g}$ or higher per day are more effective than lower doses at inducing and maintaining remission. 121-123 5-ASA can be started at a dose of 2.0-2.4 g per day and increased up to $4.8 \mathrm{~g}$, if needed. ${ }^{114,123}$ Dosing of 5-ASA once a day has similar efficacy to divided doses and could increase adherence. ${ }^{114,123}$ Patients typically see a response within 14 days, but this response might take up to 8 weeks for symptomatic remission. ${ }^{114}$ 5-ASA drugs have also been shown to be effective at maintaining remission, and patients who achieve remission with 5-ASA should continue on the same medication. ${ }^{114}$

Patients who do not respond or do not achieve remission on 5-ASA drugs can be treated with corticosteroids. Rectal corticosteroids can be tried as a second-line add-on therapy to induce remission in proctitis or left-sided ulcerative colitis. Topical 5-ASA is superior to topical corticosteroids at inducing remission (OR 2.01, 95\% CI 1.41-2.88). ${ }^{114}$ However, clinical and endoscopic improvement could be higher when combining rectal 5-ASA and corticosteroids. ${ }^{124}$ Additionally, rectal corticosteroids can be administered as foam formulations that are often better tolerated than enemas by patients with active distal ulcerative colitis. ${ }^{114}$ Oral corticosteroids are needed to induce remission in patients with mild to moderate disease who are not benefiting from 5-ASA treatment. Oral steroids with minimal systemic activity (due to high first-pass liver metabolism) such as budesonide- 
multimatrix and prolonged release beclomethasone dipropionate are effective at inducing remission in ulcerative colitis. ${ }^{125-127}$ Given the lower risk for systemic side-effects, these drugs should be considered as alternative first-line induction drugs for mild to moderate ulcerative colitis, failing 5-ASA. Systemic glucocorticoids are effective at inducing remission in ulcerative colitis with a number needed to treat of three. ${ }^{128}$ The typical starting dose is 40-60 mg prednisone daily, or the equivalent oral steroid. ${ }^{82}$ Response should be seen within 2 weeks and then steroids can be tapered. No defined tapering schedule exists, but a common approach is to taper by $5-10 \mathrm{mg}$ per week until reaching $20 \mathrm{mg}$, then decrease by 2.5-5 mg per week until completed. ${ }^{82,118}$ Corticosteroids should not be used for maintenance of remission because of a lack of long-term efficacy and risk of side-effects. ${ }^{114}$ If remission is achieved using corticosteroids, 5-ASA can be considered for maintenance in patients with a mild flare who were recently diagnosed or are naive to 5-ASA. However, patients with poor prognostic factors (young age of disease onset, extensive colitis, deep ulcerations), who require two or more courses of steroids in a year or are unable to effectively taper off steroids, should step-up therapy and start treatment with drugs such as thiopurines or biological drugs (anti-TNF-a or anti-integrin therapy). ${ }^{114}$

\section{Moderate to severe disease}

Patients with moderate to severe colitis should be managed with thiopurines or biological drugs, or both (figure 5). Thiopurines (azathioprine or 6-mercaptopurine) can be used in patients with steroid-dependent moderate to severe disease to maintain remission. Several small studies ${ }^{129,130}$ reported the modest efficacy of methotrexate in ulcerative colitis, but results of a clinical trial ${ }^{131}$ were mixed; therefore, its role in ulcerative colitis treatment is still being investigated.

Anti-TNF-a drugs, such as infliximab, adalimumab, and golimumab, are effective at inducing and maintaining remission in moderate to severe disease. ${ }^{132-135}$ Infliximab can also be used in patients admitted to hospital with severe ulcerative colitis and remains the most widely used biological for ulcerative colitis. ${ }^{132,133}$ Azathioprine alone is less effective than in combination with infliximab to achieve both clinical remission and endoscopic healing, while the difference is statistically significant only for endoscopic healing between azathioprine alone and infliximab monotherapy (SUCCESS trial). ${ }^{136}$

A new class of biological drugs, anti-adhesion molecule inhibitors, are now available. ${ }^{68}$ Vedolizumab blocks the gut-homing a $4 \beta 7$ integrin and is approved for moderate to severe ulcerative colitis, refractory to standard medications. On the basis of efficacy and safety data, vedolizumab could be considered as a first-line biological for ulcerative colitis. ${ }^{137}$

\section{Acute severe ulcerative colitis}

Patients with acute severe ulcerative colitis, defined as six or more bloody bowel movements per day and at least one of the following: pulse rate $>90$ beats per min, temperature $>37.8^{\circ} \mathrm{C}$, haemoglobin count $<10.5 \mathrm{~g} / \mathrm{dL}$, or ESR $>30 \mathrm{~mm} / \mathrm{h}$, should be admitted to a tertiary care centre. ${ }^{69}$ Acute severe ulcerative colitis is associated with significant morbidity and mortality of approximately $1 \% .{ }^{138}$ Patients are initially treated with intravenous corticosteroids to which approximately $65 \%$ will respond. ${ }^{139}$ For patients not responding to 
intravenous corticosteroids within 3 to 5 days, rescue medical therapy with either ciclosporin or infliximab can be attempted. Both drugs are equally efficacious in acute severe ulcerative colitis. ${ }^{140,141}$ Delays in surgery can increase postoperative complications and mortality increases significantly after 7 days. ${ }^{142,143}$ If there is no response to one of these drugs, colectomy should be performed. Further discussion of acute severe ulcerative colitis is in the appendix.

\section{Surgery}

Absolute indications for surgery include uncontrolled haemorrhage, perforation, and colorectal carcinoma or dysplastic lesions not amenable to endoscopic removal. ${ }^{82,144}$ Surgery is also indicated in refractory acute severe ulcerative colitis or medically refractory disease. ${ }^{82}$ The most commonly performed surgery for ulcerative colitis is restorative proctocolectomy with ileal pouch-anal anastomosis (IPAA). When surgery is emergent or urgent, it is typically done in two or three stages starting with a subtotal colectomy and creation of a temporary ileostomy (first stage) to decrease the risk of immediate postoperative complications such as anastomotic leak or pelvic sepsis. ${ }^{145}$ The ileal pouch is then created and anastomosed to the anal canal with a diverting ileostomy (second stage), which is eventually taken down to restore intestinal continuity (third stage). IPAA surgery should be done in high-volume referral centres where pouch failure rates are lower. ${ }^{146}$

Early postoperative complications following IPAA can occur in up to $33 \%$ of patients. ${ }^{147}$ Excluding pouchitis, late complications, such as bowel obstructions and strictures, can occur in as many as $30 \%$ of patients with pouch failure rates up to $5 \% .{ }^{145,146} \mathrm{~A}$ common concern related to IPAA is decreased fertility and increased sexual dysfunction. ${ }^{148}$ Laparoscopic restorative proctocolectomy with IPAA is associated with a significantly higher prevalence of pregnancy than open surgery, and has a similar prevalence of infertility compared with controls who had an appendectomy. ${ }^{149,150} \mathrm{Up}$ to $25 \%$ of men might experience erectile dysfunction or retrograde ejaculation following IPAA, but satisfaction with sexual life might not be different or could even improve following surgery because of the negative effects of active ulcerative colitis on sexuality. 151

Pouchitis is a non-specific inflammatory condition of the ileal pouch and is the most commonly encountered postoperative issue following IPAA. ${ }^{152}$ Up to $46 \%$ of patients who had IPAA will have at least one episode of pouchitis, showing that colectomy should not be presented as a cure for ulcerative colitis. ${ }^{153}$ At baseline, patients can have four to seven daily bowel movements, but pouchitis typically presents with increased frequency, urgency, incontinence, or abdominal discomfort. ${ }^{153}$ Most episodes can be successfully treated by $2-4$ weeks of ciprofloxacin (1000 mg daily) or metronidazole ( $20 \mathrm{mg} / \mathrm{kg}$ daily); one small trial $^{154}$ suggested that ciprofloxacin could be more effective than metronidazole. ${ }^{152,154} 10$ $15 \%$ of patients can develop chronic pouchitis with frequent relapses or symptoms persisting beyond 4 weeks of treatment. ${ }^{152}$ Patients might often have residual rectal tissue, referred to as a rectal cuff, at the anastomosis between the ileum and anal canal. This area can become inflamed leading to cuffitis, which, in contrast with pouchitis, typically presents with bleeding and can usually be successfully treated with 5-ASA suppositories. ${ }^{152}$ 


\section{Treat to target, disease monitoring, and long-term management}

The treatment strategy in ulcerative colitis has evolved into a treat to target approach, in which patients are regularly assessed to ensure they are meeting strict targets for disease control. The targets for ulcerative colitis are resolution of patient reported outcomes (rectal bleeding and diarrhoea) and endoscopic remission. ${ }^{3}$ Given the importance of endoscopic healing, the colon should be directly assessed 3-6 months following the initiation of a new treatment. ${ }^{3}$ Flexible sigmoidoscopy is sufficient for assessing endoscopic healing. ${ }^{155}$ Patients should have a regular follow-up at a minimum of every 3 months until symptom resolution, and then at least every $6-12$ months with the goal of maintaining tight control. ${ }^{3}$ Once patients are in remission, non-invasive markers, such as fecal calprotectin, can be used to monitor disease activity. In a post-hoc analysis of a clinical trial, ${ }^{156}$ a fecal calprotectin cutoff of $150 \mathrm{mg} / \mathrm{kg}$ was best for endoscopic remission (sensitivity of 0.79 and specificity of $0.75)$.

When patients have symptoms suggestive of an ulcerative colitis flare, infection should be excluded and objective assessments, such as sigmoidoscopy, fecal calprotectin, or stool lactoferrin should be done. Fecal calprotectin appears to have the highest sensitivity and specificity for active inflammation. ${ }^{157,158}$ If there is objective evidence of inflammation, medications should be optimised by reviewing dosage, administration, and adherence. Therapeutic drug monitoring can ensure adequate dosing. For example, patients given azathioprine or 6-mercaptopurine can have the blood concentrations of the active metabolite, 6-thioguanine, checked to ensure an adequate therapeutic amount. ${ }^{159}$ Assessment of antiTNF-a drug concentrations can similarly be of clinical use (appendix p 21). Higher serum concentrations of infliximab and adalimumab during induction and at trough are associated with endoscopic healing and clinical remission. ${ }^{160,161}$ The results of a randomised trial showed that dosing of infliximab based on a target trough of 3-7 $\mu \mathrm{L} / \mathrm{mL}$ did not improve remission at 1 year, but did lead to more efficient drug use and a decreased risk of relapse. 162 Additionally, assays for biological concentrations provide data on the development of antidrug antibodies, which have been associated with decreased drug concentrations and loss of response. ${ }^{163}$

The major elements of chronic care for patients with ulcerative colitis are colon cancer surveillance and health maintenance. Patients with ulcerative colitis should undergo regular surveillance colonoscopy to detect dysplasia and early cancer. Patients with extensive colitis and left-sided disease should undergo a colonoscopy every 1-2 years starting 8 years after diagnosis. ${ }^{82}$ Proctitis confers no increased risk of colorectal cancer so these patients should follow standard colorectal cancer screening guidelines. ${ }^{89}$ The risk of colorectal cancer in patients with ulcerative colitis and primary sclerosing cholangitis is up to five times greater than other patients with the disease, so surveillance should begin at the time of diagnosis and continue annually. ${ }^{164,165}$ Guidelines on surveillance vary among international societies (appendix p 10). Dysplasia and neoplastic lesions in ulcerative colitis can often be nonpolypoid, flat, ill-defined, or multifocal, so a prevalent strategy has been to do four random biopsies every $10 \mathrm{~cm}$ in the colon to increase detection of neoplasia. ${ }^{89}$ Enhanced visualisation using chromo-endoscopy, by spraying the colon with methylene blue or indigo carmine and doing targeted biopsies, is recommended by the SCENIC (Surveillance for 
Colorectal Endoscopic Neoplasia Detection and Management in Inflammatory Bowel Disease Patients: International Consensus Recommendations) statement. ${ }^{144}$ Colectomy is recommended if colorectal cancer or high-grade dysplasia that is not endoscopically resectable is detected. Patients with multifocal low-grade dysplasia, dense pseudo-polyposis, or strictures limiting effective surveillance might also require surgery. 109

Patients should have their vaccination status reviewed regularly. Live vaccines are contraindicated while immunosuppressed. ${ }^{82}$ Annual influenza vaccine, tetanus and diphtheria boosters, and pneumococcal vaccine every 5 years are recommended. ${ }^{166}$ Hepatitis B status should be checked before initiating treatment with anti-TNF-a drugs and those who are not immune should be vaccinated. Patients should be screened for osteoporosis if exposed to at least 3 months of corticosteroids, are malnourished, or have typical risk factors (postmenopausal women, family history, smoking). Thiopurines increase the risk of nonmelanoma skin cancer (hazard ratio 5.9, 95\% CI 2.1-16.4) and biological drugs are associated with increased rates of melanoma (OR 1.88, 95\% CI 1.08-3.29). ${ }^{167-169}$ Patients on these medications should limit sun exposure and have annual dermatological assessments. A checklist for routine health maintenance and preventive care in inflammatory bowel disease is available for reference (appendix p 13).

\section{Future directions and controversies}

The number of drugs modulating different disease pathways is expected to expand in the near future. There are at least 27 new drugs for ulcerative colitis with either recently completed or active trials. ${ }^{170}$ One example is the oral pan-janus kinase inhibitor tofacitinib, which has shown higher rates of clinical remission than placebo in phase 2 studies. ${ }^{171}$ Etrolizumab, a subcutaneous monoclonal antibody that blocks the $\beta 7$ subunit of the heterodimeric integrins $\alpha 4 \beta 7$ and $\alpha E \beta 7$ achieved higher clinical remission rates than placebo in a phase 2 trial. ${ }^{172}$ An oral anti-a 4 integrin therapy (AJM300) significantly increased clinical remission and endoscopic healing in a phase 2 trial. ${ }^{173}$ An oral drug inhibiting sphingosine-1-phosphate receptors that blocks lymphocyte egress from lymph nodes has also shown efficacy. ${ }^{174}$ In a small trial of 5-ASA non-responders, curcumin increased endoscopic remission in mild to moderate ulcerative colitis as an add-on therapy. 175 Biosimilar biological drugs should decrease the cost of therapy. Results from initial studies with an infliximab biosimilar, CT-P13, have shown efficacy at inducing endoscopic healing in ulcerative colitis. ${ }^{176}$ However, immunogenicity and efficacy remains a concern particularly in patients switching from the originator to the biosimilar. ${ }^{177}$

Studies on the efficacy of fecal microbiota transplantation (FMT) in ulcerative colitis have yielded conflicting results. While results from one study showed no improvement in clinical and endoscopic remission at 12 weeks following two infusions of FMT product from healthy donors via a nasogastric tube, a second study showed higher endoscopic remission at 7 weeks in patients treated with weekly FMT enemas. ${ }^{178,179}$ Results from the largest randomised FMT study to date, FOCUS, ${ }^{180}$ showed a higher rate of clinical and endoscopic remission or response at 8 weeks post-FMT first administered through colonoscopy followed by enemas five times a week. Although these findings are intriguing, evidence to recommend FMT for ulcerative colitis is still insufficient. Notably, FMT for treatment of 
recurrent Clostridium difficile in patients with inflammatory bowel disease (including those on immunosuppression) appears to be safe but less efficacious. ${ }^{181}$

Another area that requires further research is determining ideal targets for treatment. The optimum level of symptom control and mucosal healing that is needed to prevent long-term complications remains to be fully understood. Histological remission could ultimately become the target for therapy in ulcerative colitis. ${ }^{182,183}$

The need for precision medicine in ulcerative colitis will be greater than ever, as clinicians will have to choose which drug to use and which molecular pathway to target. An increased understanding of pharmacogenomics, biomarkers, and clinical features that identify subpopulations of patients who will best respond to specific medications will be needed to tailor therapy to individual patients. Other future research directions include combining biological therapies and head-to-head trials to determine the most optimal therapies and how to best position new medications.

\section{Supplementary Material}

Refer to Web version on PubMed Central for supplementary material.

\section{Acknowledgments}

We would like to acknowledge and thank academic medical illustrator Jill Gregory for her wonderful help with figure conception and design. We would like to thank Jerome Waye, Mabel Ko, and Aude Marchal-Bressenot for their help in providing endoscopic and histological images. This Seminar was supported in part by the SUCCESS (Sinai Ulcerative Colitis Clinical, Experimental and System Studies) grant (GCO14-0560).

\section{References}

1. Høivik ML, Moum B, Solberg IC, et al. Work disability in inflammatory bowel disease patients 10 years after disease onset: results from the IBSEN Study. Gut. 2013; 62:368-75. [PubMed: 22717453]

2. Torres J, Billioud V, Sachar DB, Peyrin-Biroulet L, Colombel J-F. Ulcerative colitis as a progressive disease: the forgotten evidence. Inflamm Bowel Dis. 2012; 18:1356-63. [PubMed: 22162423]

3. Peyrin-Biroulet L, Sandborn W, Sands BE, et al. Selecting Therapeutic Targets in Inflammatory Bowel Disease (STRIDE): determining therapeutic goals for treat-to-target. Am J Gastroenterol. 2015; 110:1324-38. [PubMed: 26303131]

4. Magro F, Rodrigues A, Vieira AI, et al. Review of the disease course among adult ulcerative colitis population-based longitudinal cohorts. Inflamm Bowel Dis. 2012; 18:573-83. [PubMed: 21793126]

5. Cohen RD, Yu AP, Wu EQ, Xie J, Mulani PM, Chao J. Systematic review: the costs of ulcerative colitis in Western countries. Aliment Pharmacol Ther. 2010; 31:693-707. [PubMed: 20064142]

6. Bernstein CN, Wajda A, Svenson LW, et al. The epidemiology of inflammatory bowel disease in Canada: a population-based study. Am J Gastroenterol. 2006; 101:1559-68. [PubMed: 16863561]

7. Cosnes J, Gower-Rousseau C, Seksik P, Cortot A. Epidemiology and natural history of inflammatory bowel diseases. Gastroenterology. 2011; 140:1785-94. [PubMed: 21530745]

8. Loftus EV. Clinical epidemiology of inflammatory bowel disease: Incidence, prevalence, and environmental influences. Gastroenterology. 2004; 126:1504-17. [PubMed: 15168363]

9. Shapiro JM, Zoega H, Shah SA, et al. Incidence of Crohn's disease and ulcerative colitis in Rhode Island: report from the Ocean State Crohn's and Colitis Area Registry. Inflamm Bowel Dis. 2016; 22:1456-61. [PubMed: 26926039] 
10. Molodecky NA, Soon IS, Rabi DM, et al. Increasing incidence and prevalence of the inflammatory bowel diseases with time, based on systematic review. Gastroenterology. 2012; 142:46-54.e42. [PubMed: 22001864]

11. Shivananda S, Lennard-Jones J, Logan R, et al. Incidence of inflammatory bowel disease across Europe: is there a difference between north and south? Results of the European Collaborative Study on Inflammatory Bowel Disease (EC-IBD). Gut. 1996; 39:690-97. [PubMed: 9014768]

12. Bengtson M-B, Solberg C, Aamodt G, et al. Familial aggregation in Crohn's disease and ulcerative colitis in a Norwegian population-based cohort followed for ten years. J Crohns Colitis. 2009; 3:92-99. [PubMed: 21172251]

13. Loftus CG, Loftus EV, Harmsen WS, et al. Update on the incidence and prevalence of Crohn's disease and ulcerative colitis in Olmsted County, Minnesota, 1940-2000. Inflamm Bowel Dis. 2007; 13:254-61. [PubMed: 17206702]

14. Burisch J, Pedersen N, Čuković-Čavka S, et al. East-West gradient in the incidence of inflammatory bowel disease in Europe: the ECCO-EpiCom inception cohort. Gut. 2014; 63:58897. [PubMed: 23604131]

15. Benchimol EI, Mack DR, Guttmann A, et al. Inflammatory bowel disease in immigrants to Canada and their children: a population-based cohort study. Am J Gastroenterol. 2015; 110:553-63. [PubMed: 25756238]

16. Benchimol EI, Manuel DG, To T, et al. Asthma, type 1 and type 2 diabetes mellitus, and inflammatory bowel disease amongst South Asian immigrants to Canada and their children: a population-based cohort study. PLoS One. 2015; 10:e0123599. [PubMed: 25849480]

17. Carr I, Mayberry JF. The effects of migration on ulcerative colitis: a three-year prospective study among Europeans and first- and second- generation South Asians in Leicester (1991-1994). Am J Gastroenterol. 1999; 94:2918-22. [PubMed: 10520845]

18. Ng SC, Tang W, Ching JY, et al. Incidence and phenotype of inflammatory bowel disease based on results from the Asia-pacific Crohn's and colitis epidemiology study. Gastroenterology. 2013; 145:158-65. [PubMed: 23583432]

19. Sood A, Midha V, Sood N, Bhatia AS, Avasthi G. Incidence and prevalence of ulcerative colitis in Punjab, North India. Gut. 2003; 52:1587-90. [PubMed: 14570727]

20. Tozun N, Atug O, Imeryuz N, et al. Clinical characteristics of inflammatory bowel disease in Turkey: a multicenter epidemiologic survey. J Clin Gastroenterol. 2009; 43:51-57. [PubMed: 18724251]

21. Victoria CR, Sassak LY, de C Nunes HR. Incidence and prevalence rates of inflammatory bowel diseases, in midwestern of São Paulo State, Brazil. Arq Gastroenterol. 2009; 46:20-25. [PubMed: 19466305]

22. Halme L, Paavola-Sakki P, Turunen U, Lappalainen M, Farkkila M, Kontula K. Family and twin studies in inflammatory bowel disease. World J Gastroenterol. 2006; 12:3668-72. [PubMed: 16773682]

23. Moller FT, Andersen V, Wohlfahrt J, Jess T. Familial risk of inflammatory bowel disease: a population-based cohort study 1977-2011. Am J Gastroenterol. 2015; 110:564-71. [PubMed: 25803400]

24. Ananthakrishnan AN. Epidemiology and risk factors for IBD. Nat Rev Gastroenterol Hepatol. 2015; 12:205-17. [PubMed: 25732745]

25. Bernstein CN, Rawsthorne P, Cheang M, Blanchard JF. A population-based case control study of potential risk factors for IBD. Am J Gastroenterol. 2006; 101:993-1002. [PubMed: 16696783]

26. Liu JZ, van Sommeren S, Huang H, et al. Association analyses identify 38 susceptibility loci for inflammatory bowel disease and highlight shared genetic risk across populations. Nat Genet. 2015; 47:979-86. [PubMed: 26192919]

27. Jostins L, Ripke S, Weersma RK, et al. Host-microbe interactions have shaped the genetic architecture of inflammatory bowel disease. Nature. 2012; 491:119-24. [PubMed: 23128233]

28. UK IBD Genetics Consortium. Barrett JC, Lee JC, et al. Genome-wide association study of ulcerative colitis identifies three new susceptibility loci, including the HNF4A region. Nat Genet. 2009; 41:1330-34. [PubMed: 19915572] 
29. Mahid SS, Minor KS, Soto RE, Hornung CA, Galandiuk S. Smoking and inflammatory bowel disease: a meta-analysis. Mayo Clin Proc. 2006; 81:1462-71. [PubMed: 17120402]

30. Odes HS, Fich A, Reif S, et al. Effects of current cigarette smoking on clinical course of Crohn's disease and ulcerative colitis. Dig Dis Sci. 2001; 46:1717-21. [PubMed: 11508673]

31. Beaugerie L, Massot N, Carbonnel F, Cattan S, Gendre JP, Cosnes J. Impact of cessation of smoking on the course of ulcerative colitis. Am J Gastroenterol. 2001; 96:2113-16. [PubMed: 11467641]

32. Birrenbach T, Böcker U. Inflammatory bowel disease and smoking: a review of epidemiology, pathophysiology, and therapeutic implications. Inflamm Bowel Dis. 2004; 10:848-59. [PubMed: 15626903]

33. Sahami S, Kooij IA, Meijer SL, Van den Brink GR, Buskens CJ, Te Velde AA. The link between the appendix and ulcerative colitis: clinical relevance and potential immunological mechanisms. Am J Gastroenterol. 2016; 111:163-69. [PubMed: 26416189]

34. García Rodríguez LA, Ruigómez A, Panés J. Acute gastroenteritis is followed by an increased risk of inflammatory bowel disease. Gastroenterology. 2006; 130:1588-94. [PubMed: 16697722]

35. Gradel KO, Nielsen HL, Schønheyder HC, Ejlertsen T, Kristensen B, Nielsen H. Increased shortand long-term risk of inflammatory bowel disease after salmonella or campylobacter gastroenteritis. Gastroenterology. 2009; 137:495-501. [PubMed: 19361507]

36. Cornish JA, Tan E, Simillis C, Clark SK, Teare J, Tekkis PP. The risk of oral contraceptives in the etiology of inflammatory bowel disease: a meta-analysis. Am J Gastroenterol. 2008; 103:2394400. [PubMed: 18684177]

37. Ananthakrishnan AN, Higuchi LM, Huang ES, et al. Aspirin, nonsteroidal anti-inflammatory drug use, and risk for Crohn disease and ulcerative colitis: a cohort study. Ann Intern Med. 2012; 156:350-59. [PubMed: 22393130]

38. Khalili H, Higuchi LM, Ananthakrishnan AN, et al. Hormone therapy increases risk of ulcerative colitis but not Crohn's disease. Gastroenterology. 2012; 143:1199-206. [PubMed: 22841783]

39. Ungaro R, Bernstein CN, Gearry R, et al. Antibiotics associated with increased risk of new-onset Crohn's disease but not ulcerative colitis: a meta-analysis. Am J Gastroenterol. 2014; 109:172838. [PubMed: 25223575]

40. Ng SC, Tang W, Leong RW, et al. Environmental risk factors in inflammatory bowel disease: a population-based case-control study in Asia-Pacific. Gut. 2015; 64:1063-71. [PubMed: 25217388]

41. Ko Y, Kariyawasam V, Karnib M, et al. Inflammatory bowel disease environmental risk factors: a population-based case-control study of Middle Eastern migration to Australia. Clin Gastroenterol Hepatol. 2015; 13:1453-63.e1. [PubMed: 25771246]

42. Hviid A, Svanström H, Frisch M. Antibiotic use and inflammatory bowel diseases in childhood. Gut. 2011; 60:49-54. [PubMed: 20966024]

43. Soon IS, Molodecky NA, Rabi DM, Ghali WA, Barkema HW, Kaplan GG. The relationship between urban environment and the inflammatory bowel diseases: a systematic review and metaanalysis. BMC Gastroenterol. 2012; 12:51. [PubMed: 22624994]

44. Klement E, Cohen RV, Boxman J, Joseph A, Reif S. Breastfeeding and risk of inflammatory bowel disease: a systematic review with meta-analysis. Am J Clin Nutr. 2004; 80:1342-52. [PubMed: 15531685]

45. Heikkilä K, Madsen IEH, Nyberg ST, et al. Job strain and the risk of inflammatory bowel diseases: individual-participant meta-analysis of 95,000 men and women. PLoS One. 2014; 9:e88711. [PubMed: 24558416]

46. Jiang C, Ting AT, Seed B. PPAR-gamma agonists inhibit production of monocyte inflammatory cytokines. Nature. 1998; 391:82-86. [PubMed: 9422509]

47. Dubuquoy L, Jansson EA, Deeb S, et al. Impaired expression of peroxisome proliferator-activated receptor gamma in ulcerative colitis. Gastroenterology. 2003; 124:1265-76. [PubMed: 12730867]

48. Rousseaux C, Lefebvre B, Dubuquoy L, et al. Intestinal antiinflammatory effect of 5aminosalicylic acid is dependent on peroxisome proliferator-activated receptor-gamma. J Exp Med. 2005; 201:1205-15. [PubMed: 15824083] 
49. Geng X, Biancone L, Dai HH, et al. Tropomyosin isoforms in intestinal mucosa: production of autoantibodies to tropomyosin isoforms in ulcerative colitis. Gastroenterology. 1998; 114:912-22. [PubMed: 9558279]

50. Kaser A, Lee AH, Franke A, et al. XBP1 links ER stress to intestinal inflammation and confers genetic risk for human inflammatory bowel disease. Cell. 2008; 134:743-56. [PubMed: 18775308]

51. Mashimo H, Wu DC, Podolsky DK, Fishman MC. Impaired defense of intestinal mucosa in mice lacking intestinal trefoil factor. Science. 1996; 274:262-65. [PubMed: 8824194]

52. Podolsky DK, Isselbacher KJ. Glycoprotein composition of colonic mucosa. Specific alterations in ulcerative colitis. Gastroenterology. 1984; 87:991-98. [PubMed: 6090262]

53. Johansson MEV, Gustafsson JK, Holmén-Larsson J, et al. Bacteria penetrate the normally impenetrable inner colon mucus layer in both murine colitis models and patients with ulcerative colitis. Gut. 2014; 63:281-91. [PubMed: 23426893]

54. Andoh A, Imaeda H, Aomatsu T, et al. Comparison of the fecal microbiota profiles between ulcerative colitis and Crohn's disease using terminal restriction fragment length polymorphism analysis. J Gastroenterol. 2011; 46:479-86. [PubMed: 21253779]

55. Frank DN, St Amand AL, Feldman RA, Boedeker EC, Harpaz N, Pace NR. Molecularphylogenetic characterization of microbial community imbalances in human inflammatory bowel diseases. Proc Natl Acad Sci USA. 2007; 104:13780-85. [PubMed: 17699621]

56. Roediger WE, Moore J, Babidge W. Colonic sulfide in pathogenesis and treatment of ulcerative colitis. Dig Dis Sci. 1997; 42:1571-79. [PubMed: 9286219]

57. Hausmann M, Kiessling S, Mestermann S, et al. Toll-like receptors 2 and 4 are up-regulated during intestinal inflammation. Gastroenterology. 2002; 122:1987-2000. [PubMed: 12055604]

58. Senhaji N, Diakité B, Serbati N, Zaid Y, Badre W, Nadifi S. Toll-like receptor 4 Asp299Gly and Thr399Ile polymorphisms: New data and a meta-analysis. BMC Gastroenterol. 2014; 14:206. [PubMed: 25492126]

59. Hanai H, Takeuchi K, Iida T, et al. Relationship between fecal calprotectin, intestinal inflammation, and peripheral blood neutrophils in patients with active ulcerative colitis. Dig Dis Sci. 2004; 49:1438-43. [PubMed: 15481316]

60. Hart AL, Al-Hassi HO, Rigby RJ, et al. Characteristics of intestinal dendritic cells in inflammatory bowel diseases. Gastroenterology. 2005; 129:50-65. [PubMed: 16012934]

61. Buonocore S, Ahern PP, Uhlig HH, et al. Innate lymphoid cells drive interleukin-23-dependent innate intestinal pathology. Nature. 2010; 464:1371-75. [PubMed: 20393462]

62. Geremia A, Arancibia-Cárcamo CV, Fleming MPP, et al. IL-23-responsive innate lymphoid cells are increased in inflammatory bowel disease. J Exp Med. 2011; 208:1127-33. [PubMed: 21576383]

63. Fuss IJ, Neurath M, Boirivant M, et al. Disparate CD4+ lamina propria (LP) lymphokine secretion profiles in inflammatory bowel disease. Crohn's disease LP cells manifest increased secretion of IFN-gamma, whereas ulcerative colitis LP cells manifest increased secretion of IL-5. J Immunol. 1996; 157:1261-70. [PubMed: 8757634]

64. Inoue S, Matsumoto T, Iida M, et al. Characterization of cytokine expression in the rectal mucosa of ulcerative colitis: correlation with disease activity. Am J Gastroenterol. 1999; 94:2441-46. [PubMed: 10484006]

65. Fuss IJ, Heller F, Boirivant M, et al. Nonclassical CD1d-restricted NK T cells that produce IL-13 characterize an atypical Th2 response in ulcerative colitis. J Clin Invest. 2004; 113:1490-97. [PubMed: 15146247]

66. Heller F, Florian P, Bojarski C, et al. Interleukin-13 is the key effector Th2 cytokine in ulcerative colitis that affects epithelial tight junctions, apoptosis, and cell restitution. Gastroenterology. 2005; 129:550-64. [PubMed: 16083712]

67. Gerlach K, Hwang Y, Nikolaev A, et al. TH9 cells that express the transcription factor PU.1 drive T cell-mediated colitis via IL-9 receptor signaling in intestinal epithelial cells. Nat Immunol. 2014; 15:676-86. [PubMed: 24908389]

68. Feagan BG, Rutgeerts P, Sands BE, et al. Vedolizumab as induction and maintenance therapy for ulcerative colitis. N Engl J Med. 2013; 369:699-710. [PubMed: 23964932] 
69. Dignass A, Eliakim R, Magro F, et al. Second European evidence-based consensus on the diagnosis and management of ulcerative colitis part 1: definitions and diagnosis. J Crohns Colitis. 2012; 6:965-90. [PubMed: 23040452]

70. Baumgart DC, Sandborn WJ. Inflammatory bowel disease: clinical aspects and established and evolving therapies. Lancet. 2007; 369:1641-57. [PubMed: 17499606]

71. Silverberg MS, Satsangi J, Ahmad T, et al. Toward an integrated clinical, molecular and serological classification of inflammatory bowel disease: report of a Working Party of the 2005 Montreal World Congress of Gastroenterology. Can J Gastroenterol. 2005; 19(suppl A):5A-36.

72. Ananthakrishnan AN, McGinley EL, Binion DG. Excess hospitalisation burden associated with Clostridium difficile in patients with inflammatory bowel disease. Gut. 2008; 57:205-10. [PubMed: 17905821]

73. Nguyen GC, Kaplan GG, Harris ML, Brant SR. A national survey of the prevalence and impact of Clostridium difficile infection among hospitalized inflammatory bowel disease patients. Am J Gastroenterol. 2008; 103:1443-50. [PubMed: 18513271]

74. Abreu MT, Harpaz N. Diagnosis of colitis: making the initial diagnosis. Clin Gastroenterol Hepatol. 2007; 5:295-301. [PubMed: 17368227]

75. Vavricka SR, Brun L, Ballabeni P, et al. Frequency and risk factors for extraintestinal manifestations in the Swiss inflammatory bowel disease cohort. Am J Gastroenterol. 2011; 106:110-19. [PubMed: 20808297]

76. Vavricka SR, Rogler G, Gantenbein C, et al. Chronological order of appearance of extraintestinal manifestations relative to the time of IBD diagnosis in the Swiss inflammatory bowel disease cohort. Inflamm Bowel Dis. 2015; 21:1794-800. [PubMed: 26020601]

77. Harbord M, Annese V, Vavricka SR, et al. The first European evidence-based consensus on extraintestinal manifestations in inflammatory bowel disease. J Crohns Colitis. 2016; 10:239-54. [PubMed: 26614685]

78. Higgins PDR, Skup M, Mulani PM, Lin J, Chao J. Increased risk of venous thromboembolic events with corticosteroid vs biologic therapy for inflammatory bowel disease. Clin Gastroenterol Hepatol. 2015; 13:316-21. [PubMed: 25038374]

79. Nguyen GC, Bernstein CN, Bitton A, et al. Consensus statements on the risk, prevention, and treatment of venous thromboembolism in inflammatory bowel disease: Canadian Association of Gastroenterology. Gastroenterology. 2014; 146:835-48.e6. [PubMed: 24462530]

80. Grainge MJ, West J, Card TR. Venous thromboembolism during active disease and remission in inflammatory bowel disease: a cohort study. Lancet. 2010; 375:657-63. [PubMed: 20149425]

81. Ananthakrishnan AN, Cagan A, Gainer VS, et al. Thromboprophylaxis is associated with reduced post-hospitalization venous thromboembolic events in patients with inflammatory bowel diseases. Clin Gastroenterol Hepatol. 2014; 12:1905-10. [PubMed: 24632349]

82. Kornbluth A, Sachar DB, Practice Parameters Committee of the American College of Gastroenterology. Ulcerative colitis practice guidelines in adults: American College Of Gastroenterology, Practice Parameters Committee. Am J Gastroenterol. 2010; 105:501-23. [PubMed: 20068560]

83. Lennard-Jones JE, Ritchie JK, Hilder W, Spicer CC. Assessment of severity in colitis: a preliminary study. Gut. 1975; 16:579-84. [PubMed: 1183857]

84. Ho GT, Mowat C, Goddard CJ, et al. Predicting the outcome of severe ulcerative colitis: development of a novel risk score to aid early selection of patients for second-line medical therapy or surgery. Aliment Pharmacol Ther. 2004; 19:1079-87. [PubMed: 15142197]

85. Reese GE, Constantinides VA, Simillis C, et al. Diagnostic precision of anti-Saccharomyces cerevisiae antibodies and perinuclear antineutrophil cytoplasmic antibodies in inflammatory bowel disease. Am J Gastroenterol. 2006; 101:2410-22. [PubMed: 16952282]

86. Sands BE. Biomarkers of inflammation in inflammatory bowel disease. Gastroenterology. 2015; 149:1275-85.e2. [PubMed: 26166315]

87. Røseth AG, Schmidt PN, Fagerhol MK. Correlation between faecal excretion of indium-111labelled granulocytes and calprotectin, a granulocyte marker protein, in patients with inflammatory bowel disease. Scand J Gastroenterol. 1999; 34:50-54. [PubMed: 10048733] 
88. Menees SB, Powell C, Kurlander J, Goel A, Chey WD. A meta-analysis of the utility of C-reactive protein, erythrocyte sedimentation rate, fecal calprotectin, and fecal lactoferrin to exclude inflammatory bowel disease in adults with IBS. Am J Gastroenterol. 2015; 110:444-54. [PubMed: 25732419]

89. Annese V, Daperno M, Rutter MD, et al. European evidence based consensus for endoscopy in inflammatory bowel disease. J Crohns Colitis. 2013; 7:982-1018. [PubMed: 24184171]

90. Bernstein CN, Shanahan F, Anton PA, Weinstein WM. Patchiness of mucosal inflammation in treated ulcerative colitis: a prospective study. Gastrointest Endosc. 1995; 42:232-37. [PubMed: 7498688]

91. D’Haens G, Geboes K, Peeters M, Baert F, Ectors N, Rutgeerts P. Patchy cecal inflammation associated with distal ulcerative colitis: a prospective endoscopic study. Am J Gastroenterol. 1997; 92:1275-79. [PubMed: 9260788]

92. Park SH, Loftus EV, Yang S-K. Appendiceal skip inflammation and ulcerative colitis. Dig Dis Sci. 2014; 59:2050-57. [PubMed: 24705639]

93. Simpson P, Papadakis KA. Endoscopic evaluation of patients with inflammatory bowel disease. Inflamm Bowel Dis. 2008; 14:1287-97. [PubMed: 18300282]

94. Magro F, Langner C, Driessen A, et al. European consensus on the histopathology of inflammatory bowel disease. J Crohns Colitis. 2013; 7:827-51. [PubMed: 23870728]

95. Panes J, Bouhnik Y, Reinisch W, et al. Imaging techniques for assessment of inflammatory bowel disease: joint ECCO and ESGAR evidence-based consensus guidelines. J Crohns Colitis. 2013; 7:556-85. [PubMed: 23583097]

96. Schroeder KW, Tremaine WJ, Ilstrup DM. Coated oral 5-aminosalicylic acid therapy for mildly to moderately active ulcerative colitis. A randomized study. N Engl J Med. 1987; 317:1625-29. [PubMed: 3317057]

97. Lichtiger S, Present DH, Kornbluth A, et al. Cyclosporine in severe ulcerative colitis refractory to steroid therapy. N Engl J Med. 1994; 330:1841-45. [PubMed: 8196726]

98. Walmsley RS, Ayres RC, Pounder RE, Allan RN. A simple clinical colitis activity index. Gut. 1998; 43:29-32. [PubMed: 9771402]

99. Shah SC, Colombel JF, Sands BE, Narula N. Mucosal healing is associated with improved longterm outcomes of patients with ulcerative colitis: a systematic review and meta-analysis. Clin Gastroenterol Hepatol. 2016; 14:1245-55. [PubMed: 26829025]

100. Travis SPL, Schnell D, Krzeski P, et al. Developing an instrument to assess the endoscopic severity of ulcerative colitis: the Ulcerative Colitis Endoscopic Index of Severity (UCEIS). Gut. 2012; 61:535-42. [PubMed: 21997563]

101. Mosli MH, Feagan BG, Zou G, et al. Development and validation of a histological index for UC. Gut. 2015; doi: 10.1136/gutjnl-2015-310393

102. Marchal-Bressenot A, Salleron J, Boulagnon-Rombi C, et al. Development and validation of the Nancy histological index for UC. Gut. 2015; doi: 10.1136/gutjnl-2015-310187

103. Siegel CA, Whitman CB, Spiegel BM, et al. Development of an index to define overall disease severity in IBD. Gut. 2016; doi: 10.1136/gutjnl-2016-312648

104. Reinisch W, Reinink AR, Higgins PDR. Factors associated with poor outcomes in adults with newly diagnosed ulcerative colitis. Clin Gastroenterol Hepatol. 2015; 13:635-42. [PubMed: 24887059]

105. Etchevers MJ, Aceituno M, García-Bosch O, et al. Risk factors and characteristics of extent progression in ulcerative colitis. Inflamm Bowel Dis. 2009; 15:1320-25. [PubMed: 19235909]

106. Charpentier C, Salleron J, Savoye G, et al. Natural history of elderly-onset inflammatory bowel disease: a population-based cohort study. Gut. 2014; 63:423-32. [PubMed: 23408350]

107. Loftus EV, Harewood GC, Loftus CG, et al. PSC-IBD: a unique form of inflammatory bowel disease associated with primary sclerosing cholangitis. Gut. 2005; 54:91-96. [PubMed: 15591511]

108. Choi CHR, Rutter MD, Askari A, et al. Forty-year analysis of colonoscopic surveillance program for neoplasia in ulcerative colitis: an updated overview. Am J Gastroenterol. 2015; 110:1022-34. [PubMed: 25823771] 
109. Beaugerie L, Itzkowitz SH. Cancers complicating inflammatory bowel disease. N Engl J Med. 2015; 372:1441-52. [PubMed: 25853748]

110. Frolkis AD, Dykeman J, Negrón ME, et al. Risk of surgery for inflammatory bowel diseases has decreased over time: a systematic review and meta-analysis of population-based studies. Gastroenterology. 2013; 145:996-1006. [PubMed: 23896172]

111. Solberg IC, Høivik ML, Cvancarova M, Moum B, IBSEN Study Group. Risk matrix model for prediction of colectomy in a population-based study of ulcerative colitis patients (the IBSEN study). Scand J Gastroenterol. 2015; 50:1456-62. [PubMed: 26139389]

112. Siebert U, Wurm J, Gothe RM, et al. Predictors of temporary and permanent work disability in patients with inflammatory bowel disease: results of the swiss inflammatory bowel disease cohort study. Inflamm Bowel Dis. 2013; 19:847-55. [PubMed: 23446333]

113. Gower-Rousseau C, Sarter H, Savoye G, et al. the International Programme to Develop New Indexes for Crohn's Disease (IPNIC) group, International Programme to Develop New Indexes for Crohn's Disease IPNIC group. Validation of the Inflammatory Bowel Disease Disability Index in a population-based cohort. Gut. 2015; published online Dec 8. doi: 10.1136/ gutjnl-2015-310151

114. Bressler B, Marshall JK, Bernstein CN, et al. Clinical practice guidelines for the medical management of nonhospitalized ulcerative colitis: the Toronto consensus. Gastroenterology. 2015; 148:1035-58.e3. [PubMed: 25747596]

115. Jharap B, Sandborn WJ, Reinisch W, et al. Randomised clinical study: discrepancies between patient-reported outcomes and endoscopic appearance in moderate to severe ulcerative colitis. Aliment Pharmacol Ther. 2015; 42:1082-92. [PubMed: 26381802]

116. Falvey JD, Hoskin T, Meijer B, et al. Disease activity assessment in IBD: clinical indices and biomarkers fail to predict endoscopic remission. Inflamm Bowel Dis. 2015; 21:824-31. [PubMed: 25738372]

117. Regueiro M, Rodemann J, Kip KE, et al. Physician assessment of ulcerative colitis activity correlates poorly with endoscopic disease activity. Inflamm Bowel Dis. 2011; 17:1008-14. [PubMed: 20812333]

118. Dignass A, Lindsay JO, Sturm A, et al. Second European evidence-based consensus on the diagnosis and management of ulcerative colitis part 2: current management. J Crohns Colitis. 2012; 6:991-1030. [PubMed: 23040451]

119. Feagan BG, Chande N, MacDonald JK. Are there any differences in the efficacy and safety of different formulations of oral 5-ASA used for induction and maintenance of remission in ulcerative colitis? Evidence from cochrane reviews. Inflamm Bowel Dis. 2013; 19:2031-40. [PubMed: 23811638]

120. Gionchetti P, Rizzello F, Venturi A, et al. Comparison of oral with rectal mesalazine in the treatment of ulcerative proctitis. Dis Colon Rectum. 1998; 41:93-97. [PubMed: 9510317]

121. Lie MRKL, Kanis SL, Hansen BE, van der Woude CJ. Drug therapies for ulcerative proctitis: systematic review and meta-analysis. Inflamm Bowel Dis. 2014; 20:2157-78. [PubMed: 25072502]

122. Ford AC, Achkar JP, Khan KJ, et al. Efficacy of 5-aminosalicylates in ulcerative colitis: systematic review and meta-analysis. Am J Gastroenterol. 2011; 106:601-16. [PubMed: 21407188]

123. Feagan BG, Macdonald JK. Oral 5-aminosalicylic acid for maintenance of remission in ulcerative colitis. Cochrane Database Syst Rev. 2012; 10:CD000544. [PubMed: 23076890]

124. Mulder CJ, Fockens P, Meijer JW, van der Heide H, Wiltink EH, Tytgat GN. Beclomethasone dipropionate $(3 \mathrm{mg}$ ) versus 5-aminosalicylic acid $(2 \mathrm{~g})$ versus the combination of both $(3 \mathrm{mg} / 2 \mathrm{~g})$ as retention enemas in active ulcerative proctitis. Eur J Gastroenterol Hepatol. 1996; 8:549-53. [PubMed: 8823568]

125. Van Assche G, Manguso F, Zibellini M, et al. Oral prolonged release beclomethasone dipropionate and prednisone in the treatment of active ulcerative colitis: results from a doubleblind, randomized, parallel group study. Am J Gastroenterol. 2015; 110:708-15. [PubMed: 25869389] 
126. Sandborn WJ, Danese S, D'Haens G, et al. Induction of clinical and colonoscopic remission of mild-to-moderate ulcerative colitis with budesonide MMX $9 \mathrm{mg}$ : pooled analysis of two phase 3 studies. Aliment Pharmacol Ther. 2015; 41:409-18. [PubMed: 25588902]

127. Danese S, Siegel CA, Peyrin-Biroulet L. Review article: integrating budesonide-MMX into treatment algorithms for mild-to-moderate ulcerative colitis. Aliment Pharmacol Ther. 2014; 39:1095-103. [PubMed: 24641622]

128. Ford AC, Bernstein CN, Khan KJ, et al. Glucocorticosteroid therapy in inflammatory bowel disease: systematic review and meta-analysis. Am J Gastroenterol. 2011; 106:590-99. [PubMed: 21407179]

129. Kozarek RA, Patterson DJ, Gelfand MD, Botoman VA, Ball TJ, Wilske KR. Methotrexate induces clinical and histologic remission in patients with refractory inflammatory bowel disease. Ann Intern Med. 1989; 110:353-56. [PubMed: 2492786]

130. Wang Y, MacDonald JK, Vandermeer B, Griffiths AM, El-Matary W. Methotrexate for maintenance of remission in ulcerative colitis. Cochrane Database Syst Rev. 2015(8):CD007560.

131. Carbonnel F, Colombel JF, Filippi J, et al. Methotrexate is not superior to placebo for inducing steroid-free remission, but induces steroid-free clinical remission in a larger proportion of patients with ulcerative colitis. Gastroenterology. 2016; 150:380-88.e4. [PubMed: 26632520]

132. Järnerot G, Hertervig E, Friis-Liby I, et al. Infliximab as rescue therapy in severe to moderately severe ulcerative colitis: a randomized, placebo-controlled study. Gastroenterology. 2005; 128:1805-11. [PubMed: 15940615]

133. Rutgeerts P, Sandborn WJ, Feagan BG, et al. Infliximab for induction and maintenance therapy for ulcerative colitis. N Engl J Med. 2005; 353:2462-76. [PubMed: 16339095]

134. Reinisch W, Sandborn WJ, Hommes DW, et al. Adalimumab for induction of clinical remission in moderately to severely active ulcerative colitis: results of a randomised controlled trial. Gut. 2011; 60:780-87. [PubMed: 21209123]

135. Sandborn WJ, Feagan BG, Marano C, et al. Subcutaneous golimumab induces clinical response and remission in patients with moderate-to-severe ulcerative colitis. Gastroenterology. 2014; 146:85-95. [PubMed: 23735746]

136. Panaccione R, Ghosh S, Middleton S, et al. Combination therapy with infliximab and azathioprine is superior to monotherapy with either agent in ulcerative colitis. Gastroenterology. 2014; 146:392-400.e3. [PubMed: 24512909]

137. Colombel JF, Sands BE, Rutgeerts P, et al. The safety of vedolizumab for ulcerative colitis and Crohn's disease. Gut. 2016; doi: 10.1136/gutjnl-2015-311079

138. Lynch RW, Lowe D, Protheroe A, Driscoll R, Rhodes JM, Arnott IDR. Outcomes of rescue therapy in acute severe ulcerative colitis: data from the United Kingdom inflammatory bowel disease audit. Aliment Pharmacol Ther. 2013; 38:935-45. [PubMed: 24004000]

139. Turner D, Walsh CM, Steinhart AH, Griffiths AM. Response to corticosteroids in severe ulcerative colitis: a systematic review of the literature and a meta-regression. Clin Gastroenterol Hepatol. 2007; 5:103-10. [PubMed: 17142106]

140. Laharie D, Bourreille A, Branche J, et al. for the Groupe d'Etudes Thérapeutiques des Affections Inflammatoires Digestives. Ciclosporin versus infliximab in patients with severe ulcerative colitis refractory to intravenous steroids: a parallel, open-label randomised controlled trial. Lancet. 2012; 380:1909-15. [PubMed: 23063316]

141. Duijvis NW, Ten Hove AS, Ponsioen CIJ, et al. Similar short- and long-term colectomy rates with ciclosporin and infliximab treatment in hospitalised ulcerative colitis patients. J Crohns Colitis. 2016; 10:821-27. [PubMed: 26818660]

142. Kaplan GG, McCarthy EP, Ayanian JZ, Korzenik J, Hodin R, Sands BE. Impact of hospital volume on postoperative morbidity and mortality following a colectomy for ulcerative colitis. Gastroenterology. 2008; 134:680-87. [PubMed: 18242604]

143. Randall J, Singh B, Warren BF, Travis SPL, Mortensen NJ, George BD. Delayed surgery for acute severe colitis is associated with increased risk of postoperative complications. Br J Surg. 2010; 97:404-09. [PubMed: 20101648] 
144. Laine L, Kaltenbach T, Barkun A, et al. SCENIC international consensus statement on surveillance and management of dysplasia in inflammatory bowel disease. Gastroenterology. 2015; 148:639-51.e28. [PubMed: 25702852]

145. Øresland T, Bemelman WA, Sampietro GM, et al. European evidence based consensus on surgery for ulcerative colitis. J Crohns Colitis. 2015; 9:4-25. [PubMed: 25304060]

146. Burns EM, Bottle A, Aylin P, et al. Volume analysis of outcome following restorative proctocolectomy. Br J Surg. 2011; 98:408-17. [PubMed: 21254018]

147. Fazio VW, Kiran RP, Remzi FH, et al. Ileal pouch anal anastomosis: analysis of outcome and quality of life in 3707 patients. Ann Surg. 2013; 257:679-85. [PubMed: 23299522]

148. Waljee A, Waljee J, Morris AM, Higgins PDR. Threefold increased risk of infertility: a metaanalysis of infertility after ileal pouch anal anastomosis in ulcerative colitis. Gut. 2006; 55:157580. [PubMed: 16772310]

149. Bartels SAL, D’Hoore A, Cuesta MA, Bensdorp AJ, Lucas C, Bemelman WA. Significantly increased pregnancy rates after laparoscopic restorative proctocolectomy: a cross-sectional study. Ann Surg. 2012; 256:1045-48. [PubMed: 22609840]

150. Beyer-Berjot L, Maggiori L, Birnbaum D, Lefevre JH, Berdah S, Panis Y. A total laparoscopic approach reduces the infertility rate after ileal pouch-anal anastomosis: a 2-center study. Ann Surg. 2013; 258:275-82. [PubMed: 23360923]

151. Kani HT, Shen B. Male issues of the ileal pouch. Inflamm Bowel Dis. 2015; 21:716-22. [PubMed: 25437820]

152. Biancone L, Michetti P, Travis S, et al. European evidence-based consensus on the management of ulcerative colitis: special situations. J Crohns Colitis. 2008; 2:63-92. [PubMed: 21172196]

153. Shen B. Pouchitis: what every gastroenterologist needs to know. Clin Gastroenterol Hepatol. 2013; 11:1538-49. [PubMed: 23602818]

154. Shen B, Achkar JP, Lashner BA, et al. A randomized clinical trial of ciprofloxacin and metronidazole to treat acute pouchitis. Inflamm Bowel Dis. 2001; 7:301-05. [PubMed: 11720319]

155. Colombel JF, Ordás I, Ullman T, et al. Agreement between rectosigmoidoscopy and colonoscopy analyses of disease activity and healing in patients with ulcerative colitis. Gastroenterology. 2016; 150:389-95.e3. [PubMed: 26526713]

156. Sandborn WJ, Panés J, Zhang H, Yu D, Niezychowski W, Su C. Correlation between concentrations of fecal calprotectin and outcomes of patients With ulcerative colitis in a phase 2 trial. Gastroenterology. 2016; 150:96-102. [PubMed: 26376350]

157. Schoepfer AM, Beglinger C, Straumann A, et al. Fecal calprotectin more accurately reflects endoscopic activity of ulcerative colitis than the Lichtiger Index, C-reactive protein, platelets, hemoglobin, and blood leukocytes. Inflamm Bowel Dis. 2013; 19:332-41. [PubMed: 23328771]

158. Mosli MH, Zou G, Garg SK, et al. C-reactive protein, fecal calprotectin, and stool lactoferrin for detection of endoscopic activity in symptomatic inflammatory bowel disease patients: a systematic review and meta-analysis. Am J Gastroenterol. 2015; 110:802-19. [PubMed: 25964225]

159. Yarur AJ, Abreu MT, Deshpande AR, Kerman DH, Sussman DA. Therapeutic drug monitoring in patients with inflammatory bowel disease. World J Gastroenterol. 2014; 20:3475-84. [PubMed: 24707130]

160. Roblin X, Marotte H, Rinaudo M, et al. Association between pharmacokinetics of adalimumab and mucosal healing in patients with inflammatory bowel diseases. Clin Gastroenterol Hepatol. 2014; 12:80-84.e2. [PubMed: 23891927]

161. Adedokun OJ, Sandborn WJ, Feagan BG, et al. Association between serum concentration of infliximab and efficacy in adult patients with ulcerative colitis. Gastroenterology. 2014; 147:1296-1307.e5. [PubMed: 25173754]

162. Vande Casteele N, Ferrante M, Van Assche G, et al. Trough concentrations of infliximab guide dosing for patients with inflammatory bowel disease. Gastroenterology. 2015; 148:1320-29.e3. [PubMed: 25724455]

163. Ben-Horin S, Kopylov U, Chowers Y. Optimizing anti-TNF treatments in inflammatory bowel disease. Autoimmun Rev. 2014; 13:24-30. [PubMed: 23792214] 
164. Annese V, Beaugerie L, Egan L, et al. European evidence-based consensus: inflammatory bowel disease and malignancies. J Crohns Colitis. 2015; 9:945-65. [PubMed: 26294789]

165. Soetikno RM, Lin OS, Heidenreich PA, Young HS, Blackstone MO. Increased risk of colorectal neoplasia in patients with primary sclerosing cholangitis and ulcerative colitis: a meta-analysis. Gastrointest Endosc. 2002; 56:48-54. [PubMed: 12085034]

166. Sinclair JA, Wasan SK, Farraye FA. Health maintenance in the inflammatory bowel disease patient. Gastroenterol Clin North Am. 2012; 41:325-37. [PubMed: 22500521]

167. Singh S, Nagpal SJS, Murad MH, et al. Inflammatory bowel disease is associated with an increased risk of melanoma: a systematic review and meta-analysis. Clin Gastroenterol Hepatol. 2014; 12:210-18. [PubMed: 23644389]

168. Long MD, Martin CF, Pipkin CA, Herfarth HH, Sandler RS, Kappelman MD. Risk of melanoma and nonmelanoma skin cancer among patients with inflammatory bowel disease. Gastroenterology. 2012; 143:390-99.e1. [PubMed: 22584081]

169. Peyrin-Biroulet L, Khosrotehrani K, Carrat F, et al. Increased risk for nonmelanoma skin cancers in patients who receive thiopurines for inflammatory bowel disease. Gastroenterology. 2011; 141:1621-28.e1. [PubMed: 21708105]

170. Khanna R, Jairath V, Vande Casteele N, et al. Efficient early drug development for ulcerative colitis. Gastroenterology. 2016; 150:1056-60. [PubMed: 27018491]

171. Sandborn WJ, Ghosh S, Panes J, et al. Tofacitinib, an oral Janus kinase inhibitor, in active ulcerative colitis. N Engl J Med. 2012; 367:616-24. [PubMed: 22894574]

172. Vermeire S, O’Byrne S, Keir M, et al. Etrolizumab as induction therapy for ulcerative colitis: a randomised, controlled, phase 2 trial. Lancet. 2014; 384:309-18. [PubMed: 24814090]

173. Yoshimura N, Watanabe M, Motoya S, et al. safety and efficacy of ajm300, an oral antagonist of a4 integrin, in induction therapy for patients with active ulcerative colitis. Gastroenterology. 2015; 149:1775-83.e2. [PubMed: 26327130]

174. Sandborn WJ, Feagan BG, Wolf DC, et al. ozanimod induction and maintenance treatment for ulcerative colitis. N Engl J Med. 2016; 374:1754-62. [PubMed: 27144850]

175. Lang A, Salomon N, Wu JCY, et al. Curcumin in combination with mesalamine induces remission in patients with mild-to-moderate ulcerative colitis in a randomized controlled trial. Clin Gastroenterol Hepatol. 2015; 13:1444-49.e1. [PubMed: 25724700]

176. Farkas K, Rutka M, Golovics PA, et al. Efficacy of infliximab biosimilar CT-P13 induction therapy on mucosal healing in ulcerative colitis. J Crohns Colitis. 2016; doi: 10.1093/ecco-jcc/ jjw085

177. Danese S, Gomollon F, Governing Board and Operational Board of ECCO. ECCO position statement: the use of biosimilar medicines in the treatment of inflammatory bowel disease (IBD). J Crohns Colitis. 2013; 7:586-89. [PubMed: 23623738]

178. Rossen NG, Fuentes S, van der Spek MJ, et al. Findings from a randomized controlled trial of fecal transplantation for patients with ulcerative colitis. Gastroenterology. 2015; 149:110-18.e4. [PubMed: 25836986]

179. Moayyedi P, Surette MG, Kim PT, et al. Fecal microbiota transplantation induces remission in patients with active ulcerative colitis in a randomized controlled trial. Gastroenterology. 2015; 149:102-09.e6. [PubMed: 25857665]

180. Paramsoth, S; Kamm, M; Walsh, A; , et al. Multi-donor intense faecal microbiota transplantation is an effective treatment for resistant ulcerative colitis: a randomised placebo-controlled trial. 11th Congress of European Crohn's and Colitis Organisation; Amsterdam. March 16-19, 2016; OP017

181. Kelly CR, Ihunnah C, Fischer M, et al. Fecal microbiota transplant for treatment of Clostridium difficile infection in immunocompromised patients. Am J Gastroenterol. 2014; 109:1065-71. [PubMed: 24890442]

182. Zenlea T, Yee EU, Rosenberg L, et al. Histology grade is independently associated with relapse risk in patients with ulcerative colitis in clinical remission: a prospective study. Am J Gastroenterol. 2016; 111:685-90. [PubMed: 26977756]

183. Peyrin-Biroulet L, Bressenot A, Kampman W. Histologic remission: the ultimate therapeutic goal in ulcerative colitis? Clin Gastroenterol Hepatol. 2014; 12:929-34.e2. [PubMed: 23911875] 


\section{Search strategy and selection criteria}

We searched for relevant manuscripts in PubMed/MEDLINE, Embase, and Cochrane Central from their inception until March 1, 2016. The search combined the MeSH terms "ulcerative colitis" and "inflammatory bowel disease" with the subheadings "epidemiology", "etiology", "physiopathology", "innate and adaptive immunity", "diagnosis", "genetics", "diagnosis", “endoscopy", "therapy", "surveillance”, and "complications". Bibliographies of included articles were searched and experts in inflammatory bowel disease were consulted to identify additional studies. Relevant articles and abstracts published in English were critically reviewed. Priority was given to manuscripts published in the past 5 years, randomised placebo-controlled trials, and meta-analyses. 


\section{Panel: Major differential diagnoses in diagnostic examination of ulcerative colitis $^{74}$}

- Infectious colitis: bacterial, viral, fungal (histoplasmosis), mycobacterial, and Clostridium difficile

- Ischaemic colitis

- $\quad$ Segmental colitis associated with diverticulitis

- $\quad$ Radiation-induced colitis or proctitis

- Medication-induced colitis (in particular non-steroidal anti-inflammatory drugs)

- $\quad$ Crohn's disease

- $\quad$ Sexually transmitted diseases (particularly in patients with proctitis who have engaged in anal intercourse): Chlamydia trachomatis, Neisseria gonorrhoeae, herpes, and syphilis

- If predominant symptom is diarrhoea and not bleeding: coeliac disease, microscopic colitis, lactose or other food intolerances, and irritable bowel syndrome 


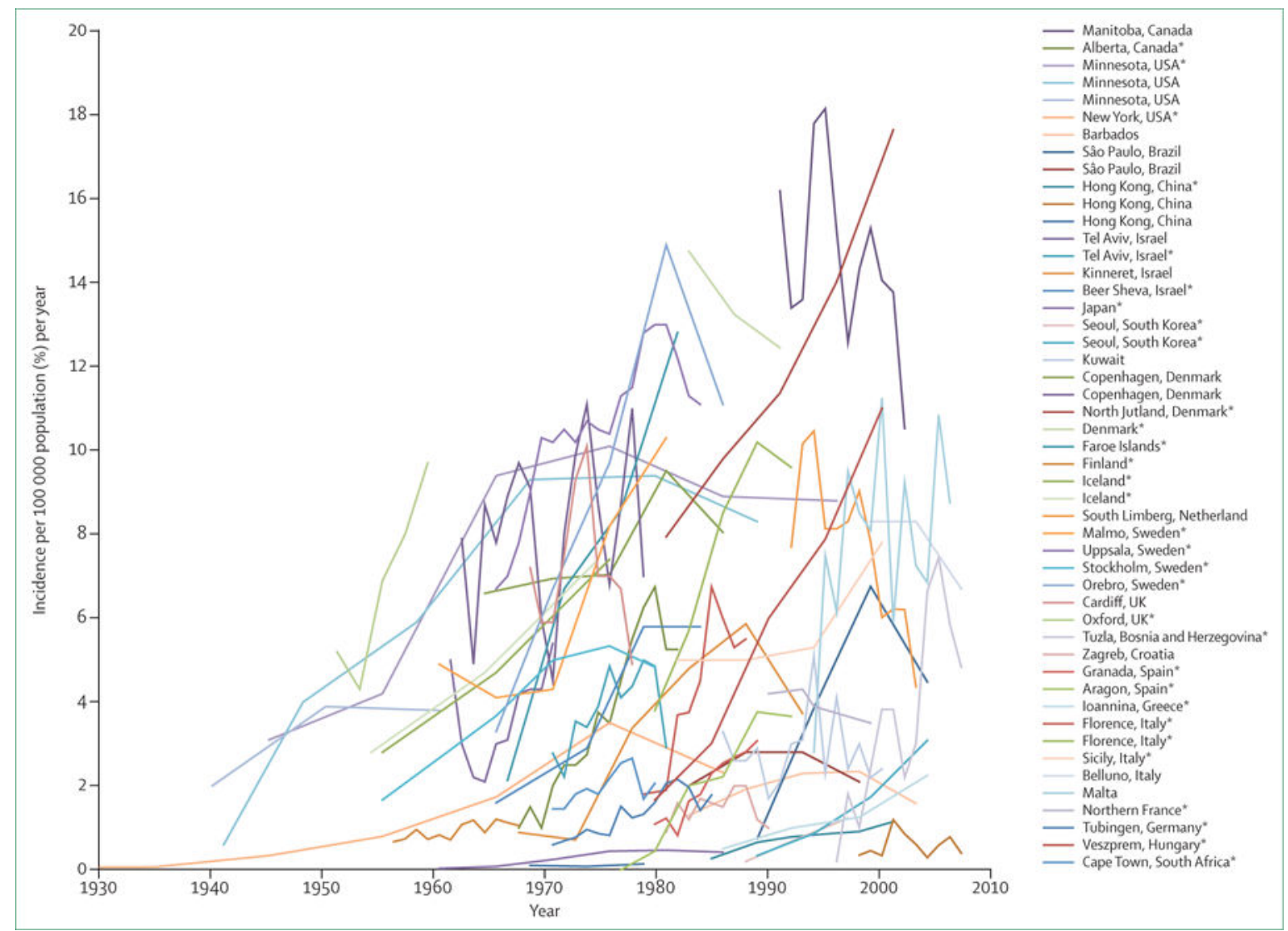

Figure 1. Increase in worldwide incidence of ulcerative colitis over time * Statistically significant increase in incidence over time $(\mathrm{p}<0.05)$. Reproduced and adapted with permission from Molodecky and colleagues. ${ }^{10}$ 


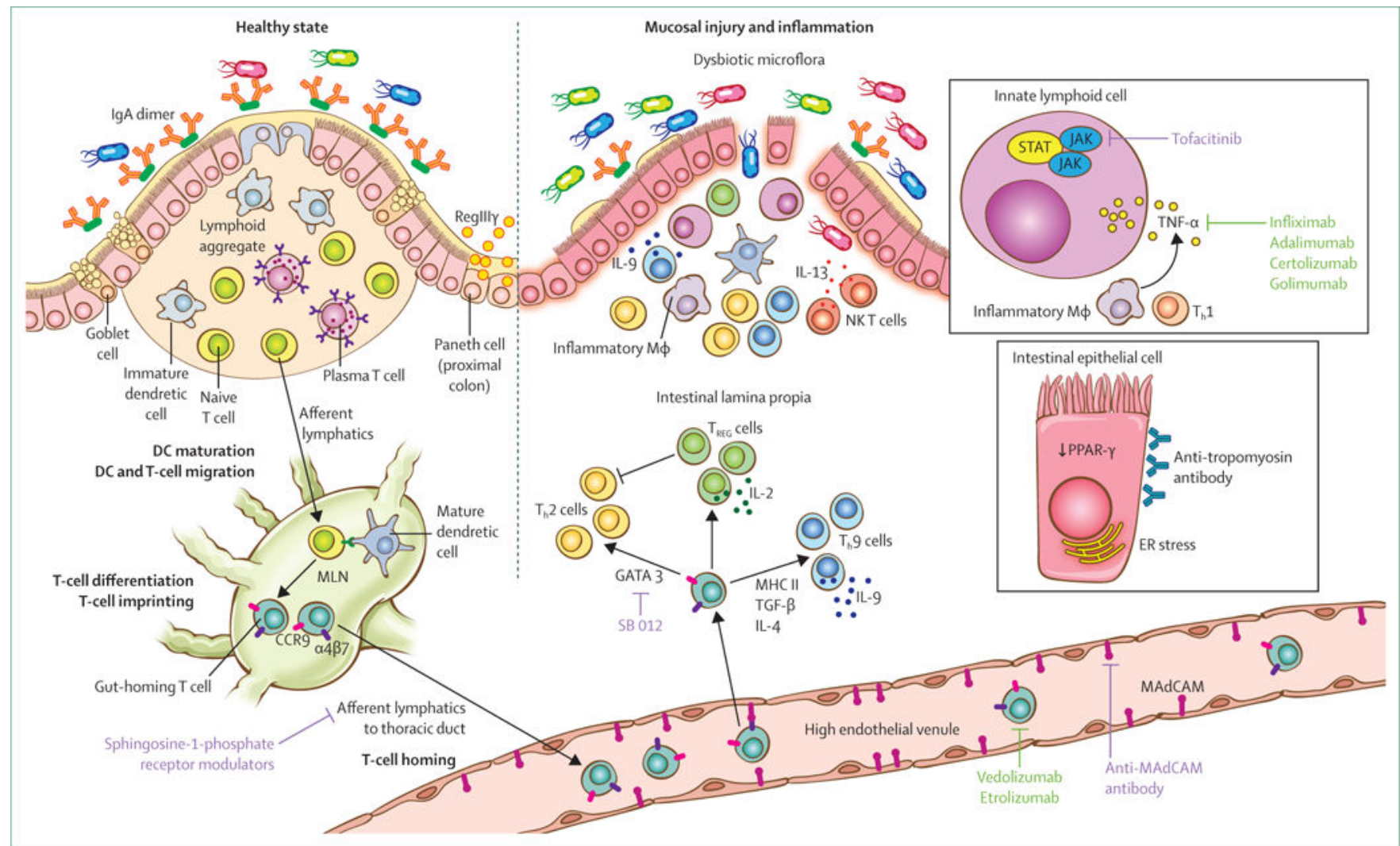

Figure 2. Overview of the intestinal immune system in the healthy state and for ulcerative colitis with a focus on proven and promising therapeutic targets

During the healthy state, barrier function is maintained by the mucus layer and epithelial cells bound across tight junctions. Additionally, IgA and antimicrobial factors such as RegIII $\gamma$ sequester luminal microflora away from the mucosal immune system. Specialised antigen-presenting cells such as dendritic cells process and present antigen to T and B cells within the draining lymph nodes, defaulting to a tolerising phenotype. Intestinal DCs also imprint $\mathrm{T}$ and B lymphocytes to express gut-homing molecules a $4 \beta 7$ and CCR9. Lymphocytes thus imprinted within the gastrointestinal tract enter the systemic circulation and upon reaching intestinal high endothelial venules, the gut-imprinted, a $4 \beta 7$-expressing lymphocytes engage locally expressed MAdCAM and egress the circulation to enter into the intestinal lamina propria. Coordinated activity of innate and adaptive immune cells maintains homoeostasis within the intestinal mucosa at steady state. Ulcerative colitis is associated with damage to the mucosal barrier (inset), allowing the luminal microflora to trigger a sustained and uninhibited inflammatory response. Among the inflammatory cells, $\mathrm{T}_{\mathrm{H}} 9$ cells perpetuate enterocyte apoptosis and inhibit mucosal healing. IL-13, produced by NK T cells, also contributes to epithelial injury. Additionally, innate lymphoid cells (inset), homeostatic at steady state, contribute to the cytokine production, perpetuating inflammation. Mucosal injury and damage is associated with dysbiosis, which perhaps contributes to the inflammatory cascade. An increasing understanding of the mucosal immune system has led to an expanding array of therapeutic targets. Of these, TNF- $\mathbf{a}$ antagonists and homing inhibitors are currently in clinical practice (green text), while the others are in early to advanced stages of clinical development (purple text). Illustration by 
Jill Gregory. Printed with permission of @Mount Sinai Health System.

IgA=immunoglobulin A. DC=dendritic cell. MAdCAM=mucosal addressin cell associated molecule. $\mathrm{IL}=$ interleukin. Th=T-helper cell. $\mathrm{T}_{\mathrm{REG}}=$ regulatory $\mathrm{T}$ cell. $\mathrm{IFN}=$ interferon, $\mathrm{M} \phi=$ macrophage. $\mathrm{TGF}=$ transforming growth factor. $\mathrm{ER}=$ endoplasmic reticulum. $\mathrm{MHC}=$ major histocompatibility complex. NK T cell=natural killer T cell. MLN=mesenteric lymph node. 

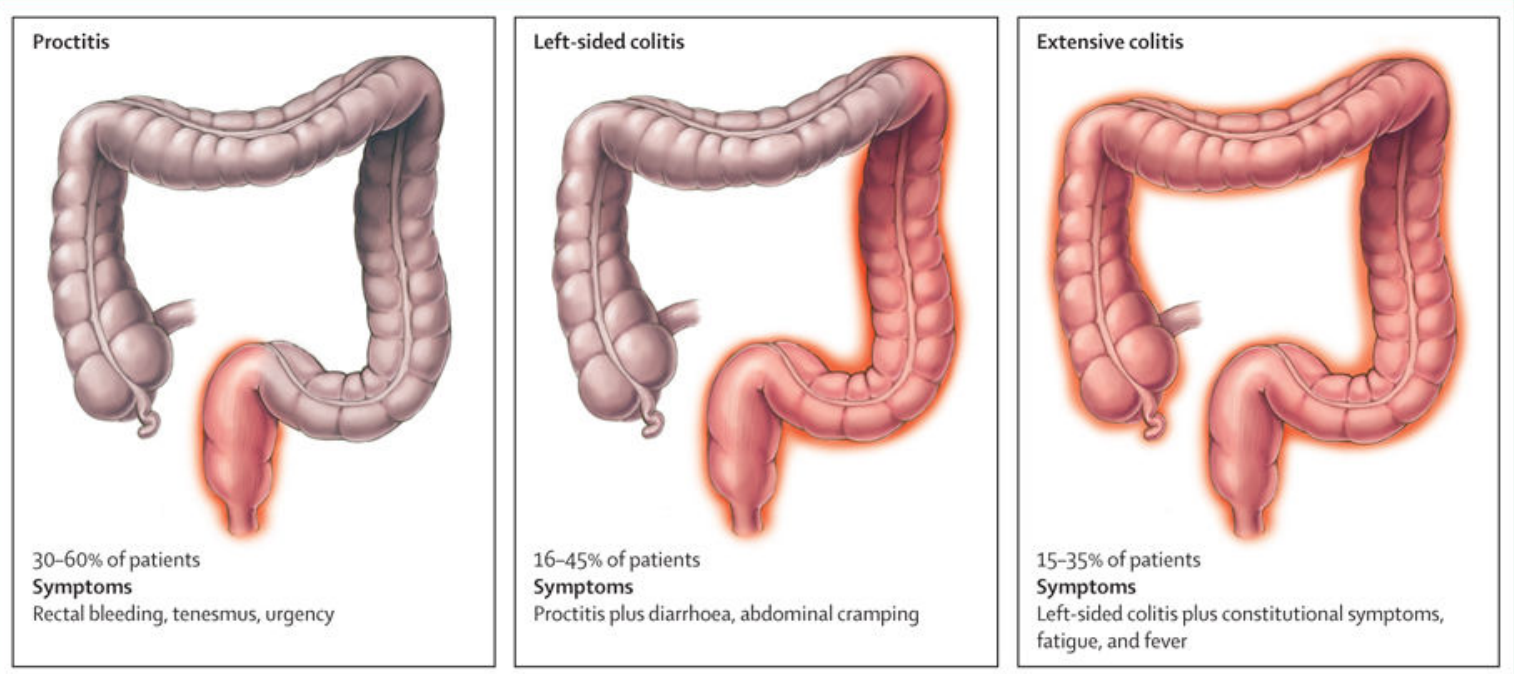

Figure 3. Ulcerative colitis phenotypes by Montreal Classification ${ }^{71}$

Symptoms and treatment strategy can differ based on extent of disease. Illustration by Jill Gregory. Printed with permission of @Mount Sinai Health System. 


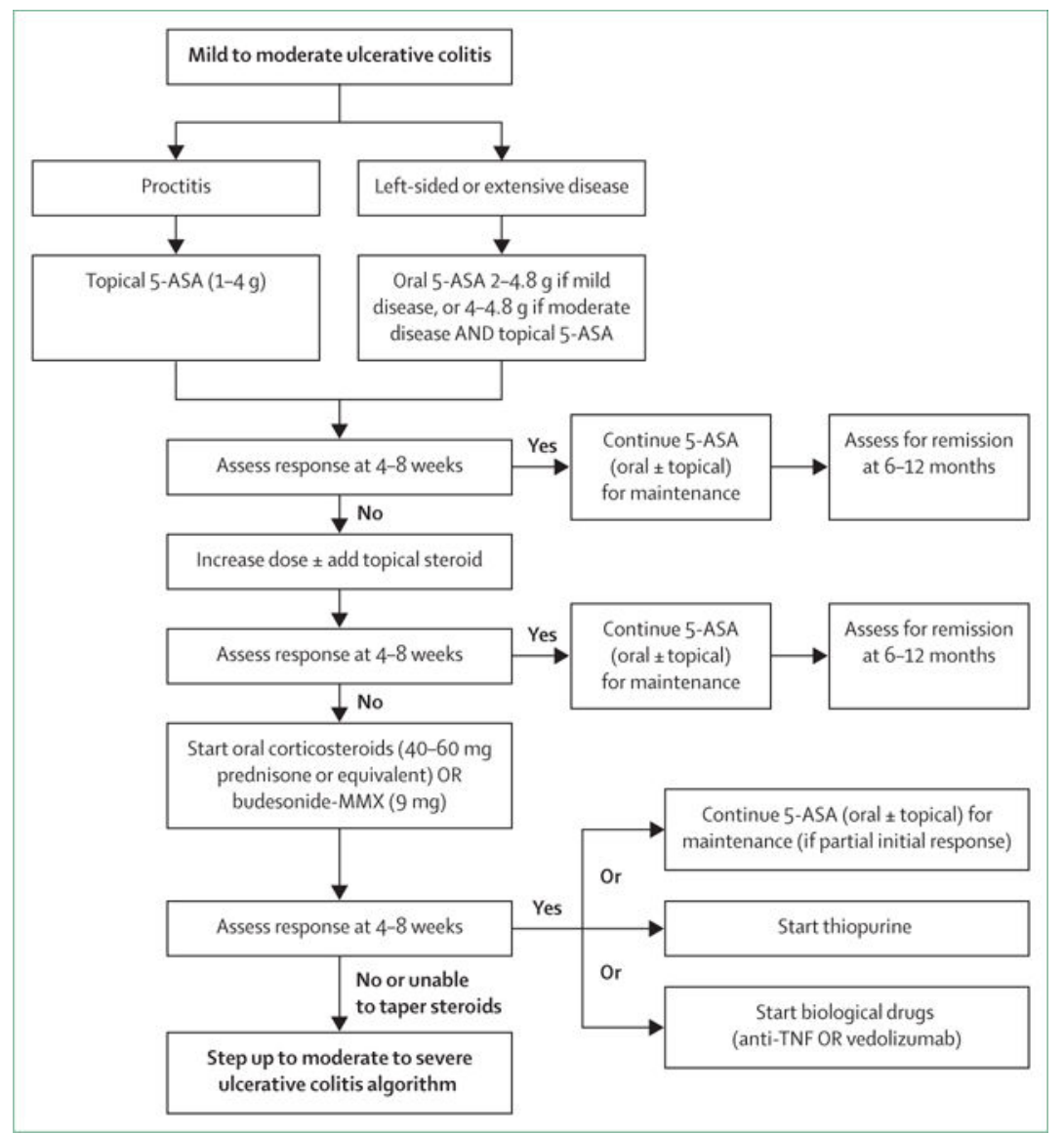

Figure 4. Suggested treatment approach algorithm for mild to moderate ulcerative colitis Based on Toronto Consensus and European Crohn's and Colitis Organisation guidelines. ${ }^{114,118}$ For patients needing and responding to steroids, the choice for maintenance medication can be either 5-ASA, thiopurine, or a biological drug. 5-ASA can be considered if partial initial response and first course of steroids. Thiopurines can be used if no response to 5-ASA, low risk of complications, and first course of steroids. Biological drugs should be used if unable to taper steroids, second course of steroids, or higher risk of complications. 5ASA=5-aminosalicylic acid. 


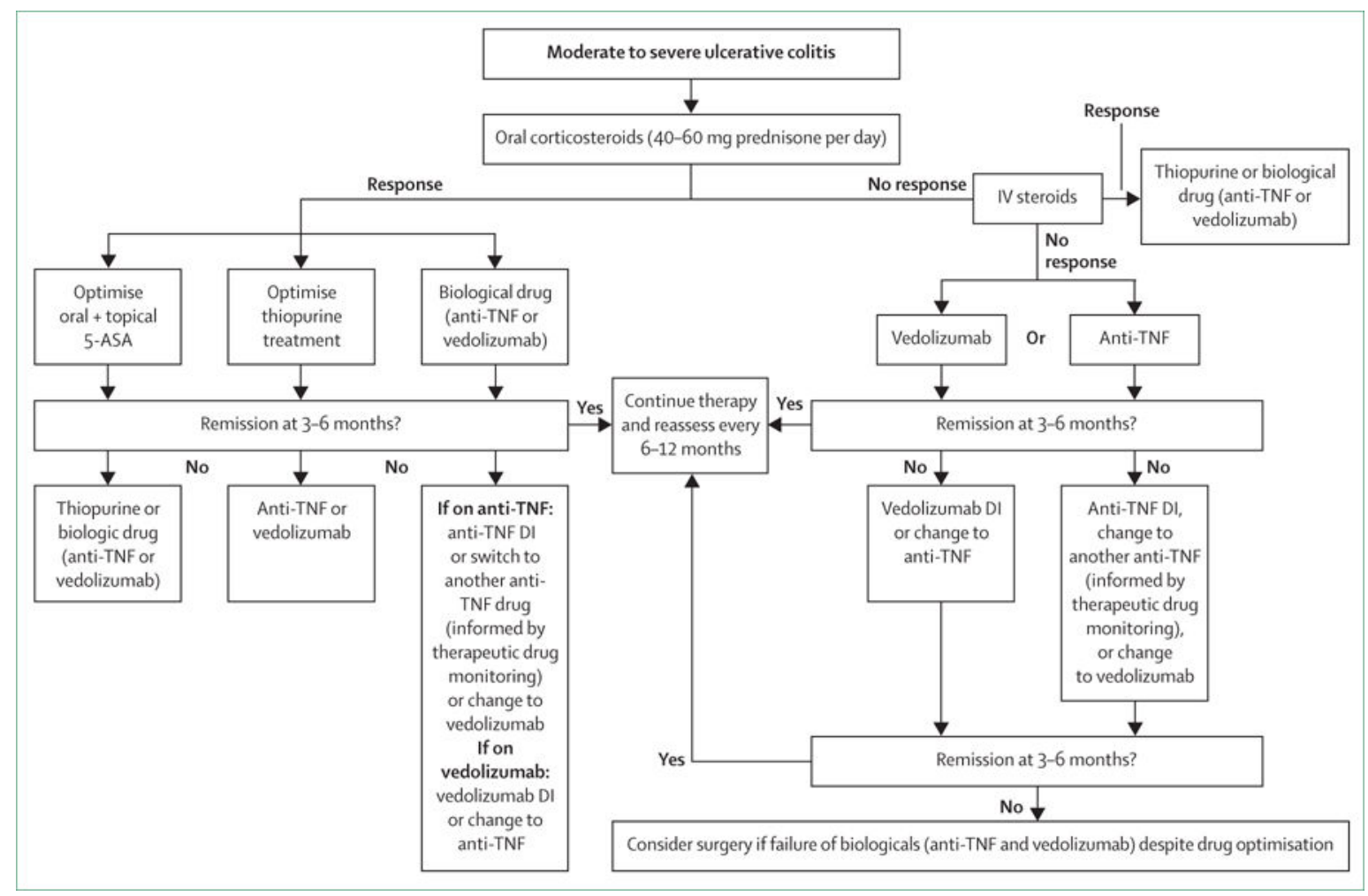

Figure 5. Suggested treatment approach algorithm for moderate to severe ulcerative colitis Based on Toronto Consensus and European Crohn's and Colitis Organisation guidelines. 114,118 5-ASA=5-aminosalicylic acid. IV=intravenous. DI=dose intensification. 